\title{
Central and Peripheral Nervous System Complications of Vasculitis Syndromes From Pathology to Bedside: Part 1—Central Nervous System
}

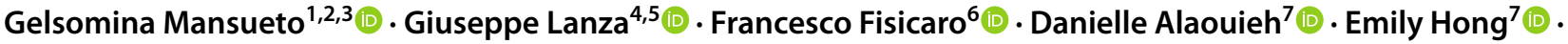

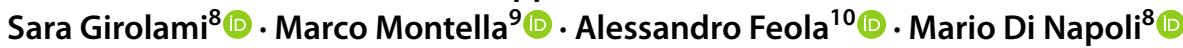

Accepted: 16 December 2021 / Published online: 9 February 2022

(c) The Author(s), under exclusive licence to Springer Science+Business Media, LLC, part of Springer Nature 2022

\begin{abstract}
Purpose of Review The aim of this review is to provide a comprehensive update on the clinical assessment, diagnosis, complications, and treatment of primary central nervous system vasculitis (PCNSV).

Recent Findings The developments in neuroimaging, molecular testing, and cerebral biopsy have enhanced clinical assessment and decision making, providing novel insights to prevent misdiagnosis increasing diagnostic certainty. Advances in imaging techniques visualizing the wall of intracranial vessels have improved the possibility to distinguish inflammatory from non-inflammatory vascular lesions. Large recent studies have revealed a more varied histopathological pictures and disclosed an association with amyloid angiopathy. Unfortunately, therapy remains largely empiric.

Summary PCNSV is a heterogeneous group of disorders encompassing different clinical subsets that may differ in terms of prognosis and therapy. Recent evidence has described a more benign course, with good response to therapy. New diagnostic techniques will play soon a pivotal role in the appropriate diagnosis and prompt management of PCNSV.
\end{abstract}

Keywords Central nervous system · Vasculitis · Pathophysiology · Antineutrophil cytoplasmic antibody · Differential diagnosis $\cdot$ Vasculitis management $\cdot$ Vasculitis treatment $\cdot$ Glucocorticoid $\cdot$ Cyclophosphamide

\section{Introduction}

Vasculitis is a group of clinical and pathological diseases characterized by infiltration of inflammatory cells with reactive damage to blood vessel walls of different size, from large arteries to capillaries and venules. Both loss of vessel integrity, leading to rupture and bleeding, and decrease in lumen diameter, may result in downstream ischemia, necrosis, and subsequent tissue damage. Blood vessels themselves can be damaged, resulting in permanent stenosis, aneurysmal changes, or rupture [1].

The revised 2012 Chapel Hill Consensus Conference (CHCC) [1] guides the categorization of different types of both primary and secondary vasculitis based on caliber of

This article is part of the Topical Collection on Neurology of Systemic Diseases

Mario Di Napoli

mariodinapoli@katamail.com

Extended author information available on the last page of the article the vessels and based on primary localization or secondary with systemic involvement (Table 1). Classification of primary vasculitis is now by the size of the affected vessel, including large vessel, medium vessel, and small vessel vasculitis. Small vessel vasculitis affects intraparenchymal arteries, arterioles, capillaries, veins, and venules; some are related to antineutrophil cytoplasmic antibody (ANCA), while others are related to immune complex deposition. Separately there is the variable vessel vasculitis that are classified without a predominant vessel size and caliber which involve arteries, veins, and capillaries. Secondary vasculitis is the vasculitis associated with systemic diseases, mainly connective tissue disorders and the vasculitis associated with a specific cause, such as substance abuse and infections. Finally, vascular inflammation restricted to a specific organ or system, such as the vasculitis of the central nervous system (CNS) and peripheral nervous system (PNS), and immunoglobulin (Ig) G4-related disease which represent the so-called single-organ vasculitis (SOV). SOV involves arteries or veins of any size, without features of a systemic vasculitis, and 
Table 1 Classification of vasculitis and their subtypes, adapted from The revised 2012 Chapel Hill Consensus Conference (CHCC) [1]

\begin{tabular}{|c|c|c|}
\hline Type of vessel and localization & Vascular disease & Key messages and red flags \\
\hline Large vessels & Giant cell arteritis (GCA) & $\begin{array}{l}\text { Clinical Findings: mainly } \geq 50 \text { years at onset, new localized headache, temporal artery } \\
\text { tenderness or decreased temporal artery pulse, erythrocyte sedimentation rate (ESR) } \\
\text { greater than } 50 \mathrm{~mm} / \mathrm{h} \text {, Pathology: biopsy of an artery showing necrotizing arteritis with } \\
\text { a lymphomonocyte infiltrate and multinucleated giant cells with a granulomatous pat- } \\
\text { tern. Diagnosis: temporal artery biopsy is the only sure way of establishing the diagnosis } \\
\text { (false negative findings may be due to inadvertent sampling of a vasculitis-free length of } \\
\text { vessel). Red flags: if unrecognized and therefore untreated or inadequately treated, there } \\
\text { is a high likelihood of large artery complication (aortic aneurysm or dissection, large } \\
\text { artery stenosis, cervical artery stenosis, subclavian, axillary, or brachial artery stenosis). } \\
\text { Occasional findings are intracranial lesions while PNS involvement in GCA remains } \\
\text { exceedingly uncommon }\end{array}$ \\
\hline
\end{tabular}

Takayasu arteritis (TAK)

Kawasaki disease (KAW)
Clinical Findings: mainly in Asian (Japanese) women with unusual changes of the central vessels of the retina in the absence of peripheral arterial pulses associated with constitutional complaints of malaise, fever, stiffness of the shoulders, nausea, vomiting, night sweats, anorexia, weight loss, and irregularity of menstrual periods. These unspecific symptoms are present weeks to months before the local signs of vasculitis ( $2 / 3$ patients). Pathology:-Early lesions: periadventitial lymphomonocyte infiltrate.—Late lesions: inflammatory infiltrate in the media and sometimes giant cells of the Langhans type and aspects of necrosis of the media. Diagnosis: to demonstrate signs of early inflammation that include vessel wall thickening and mural inflammation, as well as, the luminal changes and, the late complications of stenosis and aneurysms using non-invasive assessment of the vessel wall and the lumen of large vessels (color-Doppler sonography, contrast-enhanced high-resolution MRI and MR angiography, contrast-enhanced computed tomography combined with computed tomography angiography, or digital subtraction angiography). PET with $18 \mathrm{~F}$-fluorodeoxyglucose detects increased FDG uptake by metabolically active cells, including inflammatory cells infiltrating the vessel wall in vasculitis. Red flags: the risk factors for ischemic events include visual loss, prior ischemic events, elevated inflammatory markers, older age at diagnosis, hypertension, ischemic heart disease, and absence of systemic manifestations. Corticosteroids are the standard of care and reduce disease-related morbidity, mortality, and improve quality of life. However, they are not curative, do not prevent relapses, and are associated with significant toxicity; they should be started while the diagnostic evaluation is in progress and continued for up to 1 year before tapering to the lowest maintenance

Clinical Findings: mainly presents in middle-aged adults with a peak at 60 years of age. The presentation includes systemic features such as fatigue, weight loss, and fever, and can involve specific organ systems including the skin, kidneys, joints, muscles, nerves, and gastrointestinal tract. Pathology: transmural lymphomonocyte inflammatory infiltrate with granulocytes and fibrinoid necrosis. The vessel lumen is often thrombosed. Diagnosis: a diagnosis of PAN can be suspected based on clinical presentation but must be confirmed with a skin or renal biopsy. Alternatively, a mesenteric or renal arteriography can be diagnostic by revealing aneurysms, constrictions, or occlusions in the vessels. Red flags: untreated PAN has a poor prognosis with the most common causes of death being renal failure and organ ischemia with resultant mesenteric, cardiac, or cerebral infarction. Hepatitis B virus (HBV) associated PAN has a worse prognosis than non-HBV PAN; more severe disease necessitates the use of cyclophosphamide in addition to glucocorticoids

Clinical Findings: KAW presents most commonly in children under 5 years old. The typical symptoms include fever, conjunctivitis, mucositis, skin findings, lymphadenopathy, and cardiovascular manifestation. Pathology: transmural lymphomonocyte inflammatory infiltrate with or without necrosis. Diagnosis: this is a clinical diagnosis made by a fever lasting greater than 5 days and the presence of 4 out of 5 of the following symptoms: conjunctival injection, oral mucous membrane changes (strawberry tongue), erythema of palms or soles, edema of hands or feet in the acute phase or periungual desquamation in the convalescent phase, Polymorphous rash, and cervical lymphadenopathy. Red flags: it is important to begin treatment with intravenous immune globulin (IVIG) as soon as possible to avoid the formation of coronary artery (CA) aneurysms in children and continue it through the first 10 days of symptoms 
Table 1 (continued)

\begin{tabular}{|c|c|c|}
\hline Type of vessel and localization & Vascular disease & Key messages and red flags \\
\hline Small vessels & $\begin{array}{l}\text { Antineutrophil cytoplasmic antibody-associated } \\
\text { (ANCA) vasculitis }\end{array}$ & $\begin{array}{l}\text { Clinical Findings: people often present with prodrome systemic symptoms such as fever, } \\
\text { anorexia, myalgias and arthralgias, followed by specific organ involvement. The ears, } \\
\text { nose, and throat (ENT), lower respiratory tract and kidneys are the most commonly } \\
\text { involved organs. Pathology: necrotizing and granulomatous vasculitis. Diagnosis: } \\
\text { Patients with history, physical exam findings and labs, such as elevated ESR and } \\
\text { C-reactive protein (CRP), suggestive of ANCA vasculitis should be tested for ANCA. } \\
\text { This can be done using indirect immunofluorescence (IIF) assay or antigen-specific } \\
\text { enzyme-linked immunosorbent assays (ELISAs). Red flags: The initial non-specific } \\
\text { systemic symptoms often lead to initial misdiagnosis, and untreated, there is a poor } \\
\text { 2-year survival rate. Common differential diagnoses at initial presentation include infec- } \\
\text { tion, joint disease, and malignancy. While long term treatment with cyclophosphamide } \\
\text { and corticosteroids improves survival rates, it also poses risks of prolonged immunosup- } \\
\text { pression }\end{array}$ \\
\hline
\end{tabular}

Microscopic polyangiitis Granulomatosis with polyangiitis

(Wegener granulomatosis)

Eosinophilic granulomatosis with polyangiitis (Churg-Strauss syndrome)

Immune-complex vasculitis

Cryoglobulinemia

IgA vasculitis

(Henoch-Schonlein purpura)

Hypocomplementemic urticarial vasculitis (anti-C1q)
Clinical Findings: these conditions typically cause systemic symptoms and include ENT, lower respiratory tract, renal and cutaneous findings. Pathology: necrotizing or granulomatous vasculitis. Lymphomonocyte inflammatory infiltrate, multinucleated giant cells and fibroblastic proliferation are distinctive features. Diagnosis: Constitutional symptoms in conjunction with specific organ involvement, such as the kidneys and respiratory tract, is suspicious for an ANCA vasculitis. Since these vasculitis are often ANCA positive, ANCA testing with IIF or ELISAs can help confirm the diagnosis, with perinuclear ANCA (p-ANCA) being most highly associated. While a positive ANCA assay is helpful diagnostically, a negative ANCA does not rule out the diagnosis. A skin or kidney biopsy is used to confirm the diagnosis before initiating long term treatment. Red flags: the presentation makes it difficult to distinguish from other systemic rheumatic diseases or other vasculitis, such as PAN, eosinophilic granulomatosis with polyangiitis, drug-induced vasculitis or even malignancy and infection

Clinical Findings: low incidence, with onset in adulthood asthma, allergies, multi-organ involvement (skin, lungs, and peripheral nerves), and blood eosinophilia. Pathology: eosinophil-rich infiltrate with necrotizing and/or granulomatous vasculitis. Diagnosis: laboratory test, tissue biopsy with finding of granulomas and eosinophils and vascular involvement (ANCA vasculitis). Red flags: treated with systemic glucocorticoids, the 5 -year survival rate has reached $70-90 \%$. The common causes of mortality result from the vasculitis aspect of the syndrome and include cardiac or renal failure, cerebral hemorrhage and status asthmaticus

Clinical Findings: when immune complexes deposit in the endothelium or the glomerular or alveolar basement membranes, it presents as palpable purpura cutaneous as well as renal and lung involvement. Systemic findings including myalgias, arthralgias and gastrointestinal issues may also be present. Pathology: deposits of immunoglobulin and/ or complement components predominantly with inflammatory reaction and necrotizing findings. Diagnosis: palpable purpura can be assessed using diascopy. Diagnosis is made through histological analysis of biopsy. Red flags: immune complex vasculitis that is confined to the skin, presenting with palpable purpura only, has a better prognosis than immune complex vasculitis with systemic involvement

Clinical Findings: necrotic ulcers, purpura, joints, peripheral nervous system, and kidneys (glomerulonephritis involvement). Pathology: deposits of cryoglobulin with inflammatory reaction and necrotizing findings. Diagnosis: lab tests specific for type I, II and III (monoclonal Ig, usually IgM or IgG; polyclonal IgMs, polyclonal IgGs, polyclonal IgMs and IgGs). Red flags: Differential diagnoses, especially in the case of mixed cryoglobulinemia, must include hematological malignancies such as myeloma, B-cell lymphoma, B-cell non-Hodgkin's lymphoma, Hepatitis C, and connective tissue disease. it is important to determine the underlying cause, which may include infection, such as Hepatitis C or HIV, or neoplastic disorders, as this may change the course of treatment for the cryoglobulinemia

Clinical Findings: rash caused by erythrocyte extravasations in the skin dermis, bleeding in the digestive tract, abdominal pain, joint pain and swelling, renal involvement. Pathology: leukocytoclastic vasculitis with leukocyte fragments in the perivascular interstitial tissue and deposits of IgA and $\mathrm{C} 3$ and associated erythrocyte extravasations. Diagnosis: in adults, biopsy with identification of IgA remains the only valid diagnostic method after the suspicion has been formulated. In a child with purpura on the lower limbs, diagnosis is made if abdominal pain, presence of IgA on histology, arthritis, or renal impairment is present. Laboratory tests are not specific as well as urinary tests but can be useful in excluding other pathologies. Red flags: in some cases, end-stage renal failure may occur more than 10 years after onset of Ig A vasculitis. It is recommended to monitor urinary sediment for at least 6-months in patients without renal impairment and longer for those with renal impairment

Clinical Findings: urticarial lesions, systemic manifestations (musculoskeletal, ocular, gastrointestinal, pulmonary and kidney involvement). Pathology: predominant perivascular eosinophilic infiltrate. Diagnosis: hypocomplementemia; anti-C1q antibodies are detected in only half of the patients. Red flags: important differential diagnoses include systemic lupus erythematosus and the mixed cryoglobulinemia, which also present with low complement levels and involvement of multiple organ systems 
Table 1 (continued)

\begin{tabular}{|c|c|c|}
\hline Type of vessel and localization & Vascular disease & Key messages and red flags \\
\hline Variable vessel sizes & Behcet's disease & $\begin{array}{l}\text { Clinical Findings: oral aphthae, genital ulcers, skin and eye lesions, and flares of acute } \\
\text { inflammation. Vascular lesions can occur in large, medium, or small arteries and veins. } \\
\text { Patients with suspected vascular Behcet's usually present with aneurysms in young } \\
\text { patients, saccular aneurysms without arteriosclerotic degeneration, arterial occlusion } \\
\text { or pseudoaneurysm after puncture, superior vena cava syndrome, bilateral deep vein } \\
\text { thrombosis, recurrent superficial thrombophlebitis, or skin ulcers of the lower leg. } \\
\text { Pathology: lymphocytic infiltrate and granulomatosis findings. Diagnosis: diagnosis is } \\
\text { made by clinical symptoms. Red flags: vascular Behcet's has a high risk of postoperative } \\
\text { complications and so surgery is not an established treatment. Arterial occlusion is not } \\
\text { developed through ordinary atherosclerotic occlusions and thus endovascular treatment } \\
\text { should be chosen with caution. Deep vein thrombosis can be treated with ordinal throm- } \\
\text { bolytic therapy after anticoagulant therapy }\end{array}$ \\
\hline
\end{tabular}

Cogan syndrome

Single organ vasculitis (SOV)
Idiopathic aortitis (IgG4)

Systemic lupus erythematosus vasculitis (SLE)
Clinical Findings: inflammatory eye disease and vestibuloauditory symptoms primarily in young white adults. $30 \%$ have systemic manifestations like systemic vasculitis, aortitis, musculoskeletal complaints, and neurological symptoms. Pathology: acute inflammatory infiltrate, transmural necrosis, fibrosis. Like PAN. Diagnosis: can be made when the pattern of autoimmune type vestibuloauditory symptoms are associated with inflammatory eye disease or when the time of onset between the ophthalmologic and vestibuloauditory symptoms is more than 2 years. CT and MRI are often normal. Red flags: progressive hearing loss can lead to deafness in two years, although there is often stabilizing response to corticosteroid treatment. Immunosuppressive drugs can be used as well although the risks and benefits should be discussed

Primary angiitis of the central nervous system (PACNS) Clinical Findings: stroke, encephalopathy, headache, and seizures are major clinical presentations. PACNS mainly affects younger stroke patients lacking cerebrovascular risk factors. Pathology: lymphocytic pattern with T lymphocytes arranged around the vessels. Granulomatous pattern with CD-68 macrophages arranged. Necrotizing pattern with lymphocytes and vessel necrosis. Diagnosis: a combination of clinical presentation, imaging findings (MRI and angiography), brain biopsy, and laboratory and cerebrospinal fluid (CSF) values. Red flags: this disease has significant morbidity and mortality, necessitating early diagnosis and treatment. Involvement of larger or proximal cerebral vessels seems to be associated with higher mortality

Clinical Findings: classically an acute, relapsing multifocal neuropathy but can present as a slowly progressive neuropathy without asymmetries. The lower limbs are usually affected. Pathology: perivascular acute or chronic inflammation, vascular damage, fibrinoid necrosis, leukocytoclasia, vascular deposition of complement, IgM, or fibrinogen. Diagnosis: can only be diagnosed with a nerve biopsy looking for vessel wall inflammation and damage. Probable diagnosis is possible if biopsy findings are suspicious. No radiographic techniques have been established for diagnosis. Red flags: the presence of neuropathy is not associated with overall mortality

Clinical Findings: risk factors for aortitis include advanced age, history of connective tissue disease, diabetes mellitus, and heart valve pathology. Pathology: lymphoid and plasma cells aggregate (IgG4) in the adventitia and in the media, fibrinoid necrosis. Diagnosis: workup should focus on excluding malignant, infectious, or systemic causes of vasculitis. Imaging with CT or MRI with IV administration of contrast material is critical for diagnosis. Biopsy can be used to confirm a diagnosis. Red flags: patients are at risk for aneurysm and dissection

Clinical Findings: rheumatoid vasculitis can affect any organ of the body although the most common sites are the skin (purpura, lesions, focal digital lesions, ulcers, pyoderma) and peripheral nerves (distal sensory or motor neuropathy, mononeuritis multiplex). Pathology: perivascular inflammatory infiltrate of $\mathrm{T}$ lymphocytes, plasma cells, macrophages. Diagnosis: rheumatoid vasculitis occurs almost exclusively in people with seropositive nodular RA. Inflammation of more than three layers of the vessel is a sensitive and specific finding to distinguish rheumatoid vasculitis from RA without vasculitis. Definitive diagnosis may require biopsy as angiographic findings are non-specific. Red flags: studies have shown an association between smoking and the development of rheumatoid vasculitis. There is significant morbidity and mortality associated with rheumatoid vasculitis, especially when the heart, bowel, or kidney are involved

Clinical Findings: a diverse clinical spectrum of SLE-related vasculitis exists due to inflammatory involvement of all sizes of vessels. Cutaneous lesions, often on the fingertips and palms, are most frequent although medium and large vessel vasculitis may present with visceral affection. Episodes of vasculitis are not always associated with disease activity. Pathology: perivascular patchy lymphomonocyte inflammatory infiltrate. Diagnosis: Cutaneous vasculitis is confirmed with biopsy. CNS vasculitis can be detected with brain biopsy but due to its risks, neuroimaging with angiography or MRI in combination with clinical features can allow diagnosis. Red flags: medium and large vessel vasculitis can lead to mesenteric vasculitis, pulmonary hemorrhage, or mononeuritis multiplex, which are life-threatening conditions 
Table 1 (continued)

\begin{tabular}{lll}
\hline Type of vessel and localization & Vascular disease & Key messages and red flags \\
\hline Vasculitis associated with infection & Acute bacterial meningitis vasculitis & $\begin{array}{c}\text { Clinical Findings: pneumococcal infection can rarely cause vasculitis due to inflammation } \\
\text { through bacterial bloodstream invasion and most commonly affects elderly individuals. } \\
\text { Cerebral vascular involvement can lead to hearing loss, hydrocephalus, parenchymal } \\
\text { infarctions, cerebritis, and hemorrhages. Pathology: prevalent lymphogranulocyte infil- } \\
\text { trate. The granulomatous pattern and necrotizing findings may be present. Diagnosis: }\end{array}$ \\
& $\begin{array}{l}\text { Cerebral angiography typically shows vascular changes in segments of the arteries. Small } \\
\text { vessels may show loss of arterial autoregulation shown by focal abnormal parenchymal } \\
\text { blush associated with hyperperfusion. Red flags: ischemic and hemorrhagic strokes are }\end{array}$ & common complications of bacterial meningitis and are associated with greater mortality
\end{tabular}

Mycobacterial tuberculous vasculitis Atypical mycobacteriosis vasculitis

Varicella Zoster Virus (VZV) vasculitis

Human immunodeficiency virus (HIV) type-1/AIDS vasculitis

COVID-19 (SARS-Cov-2) Vasculitis
Clinical Findings: vasculitis symptoms like, typical tuberculous skin lesions, petechial rash, as well as enlarged cervical lymph nodes and other signs of tubercular infection. Pathology: lymphocytic infiltrate with necrotizing findings and epithelioid granulomatous pattern. The infiltrate with granulocytes and necrotizing findings is very evident in atypical mycobacterial and in fungal disease. Diagnosis: imaging can be used to evaluate vessels for inflammatory change. Timeline of presentation of tubercular infection and vasculitis should inform diagnosis. Red flags: tuberculosis vasculitis can lead to brain infarcts and stroke as well as thrombosis of the anterior spinal artery and infarction of the spinal cord

Clinical Findings: the first clue of VZV vasculitis is a history of recent zoster or varicella rash. Most VZV vasculopathies develop within 6 weeks but can present up to 4 months after rash. Headache is the most common symptom, along with focal neurological symptoms and isolated vision loss. Immunocompromised patients are especially at risk for VZV vasculitis. Pathology: granulomatous vasculitis with multinucleated giant cells and/or epithelioid macrophages and may resemble giant cell arteritis. Leukocytoclastic vasculitis (including Henoch-Schönlein purpura) has also been seen. Diagnosis: diagnosis can be confirmed by vascular imaging and laboratory analysis for VZV infection. Ischemic infarcts are usually ovoid, well-defined, involve both cortical and deep structures, and in VZV vasculitis, are usually at the gray-white matter junction. Both small and large vessels may show segmental stenosis with poststenotic dilatation. CT and MR angiography are commonly used but conventional cerebral angiogram is the gold standard. Red flags: zoster is a short- and long-term risk factor for stroke. Some cases of cerebral sinus thrombosis, cervical vessel dissection, and intracranial aneurysms have been associated with CNS VZV infection. Testing for VZV should include both serum and CSF anti-VZV IgM and IgG titers as well as VZV PCR

Clinical Findings: almost all causes of vasculitis can be seen in HIV positive patients and it is unclear whether HIV and vasculitis are causally or coincidentally related. Other presenting conditions related to different systems and organs may mask the vasculitis and the concurrence of other pathogens like EBV, HBV, and CMV complicate presentation. Pathology: almost every pattern of small, medium, and large vessel vasculitis has been observed. Leukocytoclastic vasculitis of the vasa vasorum or periadventitial vessels is often restricted to a small number of visceral vessels and usually affects the skin, peripheral nerve and skeletal muscle, and the central nervous system, although the lung, gastrointestinal tract, oropharynx, and kidney can also be affected. Diagnosis: diagnosis of infective vasculitis is dependent on serology, culture, light microscopy, immunohistochemistry, and in situ hybridization. MRI findings of CNS vasculitis in HIV-positive patients include white matter changes, multiple cavitary infarcts, thrombus formation, stenosis, and microaneurysms of the large cerebral vessels. Small vessel angiitis may require brain biopsy. Red flags: HIV-positive patients with large vessel vasculitis developed more vascular complications, responded less to antiretroviral therapy, and had worse outcomes than HIV-negative patients with large vessel vasculitis. Primary angiitis of the CNS, although rarely found in HIV-positive patients, is associated with high mortality

Clinical Findings: it is unclear whether SARS-CoV-2 and vasculitis are causally or coincidentally related. Only case reports and small radiological series are reported in literature. In many cases the available data are insufficient to establish the diagnosis of vasculitis due to the lack of SARS-CoV-2 PCR finding in the CSF, biopsy, and pathological data

Pathology: Lymphocytic vasculitis, including infiltration of vessel walls by lymphocytes (predominantly CD3 + T cells with a sparse admixture of CD20 + B cells) with endothelial hypertrophy. Edematous and gliotic white matter changes with extensive lymphoplasmacytic perivascular inflammation together with parenchymal necrosis and dystrophic calcification. The presence of patchy brain microbleeds clearly distinct from hypertension-related hemorrhage, critical illness-associated microbleeds and cerebral amyloid angiopathy. Diagnosis: diagnosis of SARS-Cov-2 vasculitis is dependent on serology, light microscopy, immunohistochemistry, in situ hybridization and, brain biopsy. MRI findings of CNS vasculitis in SARS-Cov-2-positive patients include white matter changes, extensive white matter microhemorrhages with an atypical involvement of the corpus callosum, and multiple cavitary infarcts. Less frequently are present stenosis and microaneurysms of the large cerebral vessels. Given the prevalent small-vessel involvement, digital subtraction angiography should be performed to characterize potential distal vessel irregularities. Vessel wall MR imaging should be performed to search for concentric vessel wall enhancement (direct sign of regional mural inflammation). Red flags: Common presentations are acute ischemic stroke, subarachnoid or cerebral hemorrhages. The data on prognosis of SARS-Cov2 vasculitis are uncertain. Based on single case reports, steroid treatment after negative nasopharyngeal PCR could be useful (IV methylprednisolone $1,000 \mathrm{mg}$ daily for 3 days, followed by an oral prednisone taper over 6 months) 
Table 1 (continued)

\begin{tabular}{|c|c|c|}
\hline Type of vessel and localization & Vascular disease & Key messages and red flags \\
\hline Other types & Vasculitis due to drugs and illicit substance abuse & $\begin{array}{l}\text { Clinical Findings: illicit drug abuse is a rare cause of histopathological verified CNS } \\
\text { vasculitis among the many potential classes of abused drugs traditionally implicated in } \\
\text { this disease. Arthralgia, myalgia, and skin rash can be seen. Pathology: acute vasculitis } \\
\text { with fresh thrombi with foreign material and granulomas when abuse is intravenously. } \\
\text { Diagnosis: illicit drug abuse is a common differential diagnosis of acquired central nerv- } \\
\text { ous system vasculitis. A likely diagnosis rests on the drug that is abused and the clinical } \\
\text { and neuroradiologic findings of a presumptive case. Hemorrhagic and non-hemorrhagic } \\
\text { stroke often preceded by vasospasm and aneurysm formation especially when the illicit } \\
\text { substances are delivered parenterally are common outcomes in confirmed cases. Red } \\
\text { flags: the complications of illicit substance use on the cerebral circulation can be highly } \\
\text { lethal. HIV/AIDS infection has a possible causative role in drug uses. Management rests } \\
\text { on avoidance of further exposure and minimizing the secondary neurotoxic effects of the } \\
\text { abused substances and polypharmacy use }\end{array}$ \\
\hline
\end{tabular}

includes the granulomatous angiitis of the brain and similar terms of primary angiitis of the CNS (PACNS; adult or childhood) primary CNS vasculitis (PCNSV), isolated or non-systemic PNS vasculitis (NSPNSV), and isolated aortitis (IgG4-related). See Table 1 for further classification and characterization of different vasculitis.

Although extensive literature and classifications exist, many neurologists still have a limited knowledge of vasculitis, partially because other specialists often diagnose and manage most of these patients. However, both CNS and PNS are frequently a major target of these disorders, including their early stages, when the clinical manifestations are often non-specific, thus causing underestimation of their actual prevalence. The typical CNS manifestation of vasculitis is a stroke, either because of SOV or neurological consequence of a systemic vasculitis. Other common CNS presentations include visual loss, encephalopathy, seizures, headache,

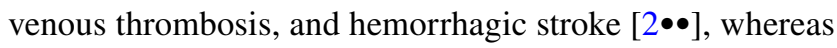
the involvement of PNS usually presents as peripheral neuropathy of different types (polyneuropathy, mononeuropathy, or multiplex mononeuropathy, and cranial neuropathy) and neuromuscular disease [3, 4]. Overall, differential diagnosis of vasculitis is challenging, and neurologists are often on the frontline of the diagnosis and treatment of these patients.

In this scenario, the management of patients with nervous system vasculitis is based on 7 main principles. Principle 1 : vasculitis are often severe diseases with potential permanent disability due to tissue ischemia and infarction and a possible fatal outcome that requires prompt recognition and therapy. Principle 2: some forms of vasculitis are associated with severe neurological complications that significantly affect patient's prognosis. Principle 3: clinical course of vasculitis can range from fulminant to very mild forms and may fluctuate in clinical signs. Principle 4: there is a likelihood of excess morbidity and mortality due to missing diagnosis and therefore undertreatment. Principle 5: histopathological confirmation of vasculitis is essential for accurate diagnosis, as well as a correct methodology for achieving it. Principle 6: empiric trials with immunosuppressive and immunomodulating therapy should never be considered as a substitute for a confirmed diagnosis of vasculitis. Principle 7: treatments are initially guided toward stabilization of the blood-brain barrier (BBB), followed by maintenance immunosuppressive therapy directed both at the humoral and cell-mediated autoimmune and inflammatory mechanisms. Physicians should be able to early diagnose and timely treat these patients in order improve prognosis and functional outcome $[1,5,6 \bullet \bullet]$.

In this review, we provide a timely update on CNS vasculitis and a practical guide for clinical neurologists in disentangling their differential diagnosis, laboratory evaluation, histological findings, and treatment of CNS vasculitis. The vasculitis affecting the PNS will be included in the companion review.

\section{Methods and Results}

To provide a comprehensive update, a PubMed-based (MEDLINE) literature review was carried out to identify all pertinent studies within the last five years (January 2016-May 2021). The following search terms were used: primary and secondary vasculitis, central nervous system, biopsy, autopsy, neuropathology, histology, morphology, encephalopathy, ischemic stroke, intracerebral hemorrhage, gliosis, necrotizing encephalopathy, encephalitis, myelitis, and inflammation.

A total of 863 articles, including those listed in the references of the retrieved studies, were screened. Then, we excluded the following items: papers different from original articles, preclinical or animal studies, non-English written papers, and any other publication that did not comply with the goal of the present review.

\section{Overview on CNS Vasculitis Pathogenesis}

The dual role of the BBB is known as a coating structure and a functional component in cerebrovascular angiogenesis and exchanges between the brain and blood compartment, although the latter function is still not completely understood. What we certainly know is 
that the BBB integrity is of critical importance, since its disruption is both a predisposing and precipitating factor of a variety of primary and secondary neurological diseases, including vasculitis [7-9]. Also, genetic background plays a crucial role as an additional predisposing factor to vasculitis [10]. Accordingly, the association between vasculitis and some human leukocyte antigen (HLA) loci that are very highly polymorphic, such as the HLA-B involved in the binding of the antigen and interactions with receptors on CD8 T cells and natural killer (NK) cells, is well known [10]. Another example is the association between PR3-ANCA vasculitis and the genes SERPINA1 (encoding alpha-1 antitrypsin), PRTN (encoding PR3), and some HLA loci, including the HLA-DP4 and HLA-DQ [11]. However, because most of vasculitis are rare diseases with a complex genetic risk conferred by hundreds of loci with a low independent effect, a genetic heritability can only account for a small proportion of cases. Indeed, only few genetic associations have been published on neurological complications of vasculitis, and these have not been replicated in independent studies [10].

Both the immune system and inflammatory responses play a pivotal role in the etiopathogenesis of CNS vasculitis, although some aspects remain unclear yet. Mechanisms of vascular damage can basically be summarized as follows [12]: (1) immune complex-mediated; (2) cell-mediated; and (3) ANCA-mediated: cytoplasmic (c-ANCA), perinuclear (p-ANCA), and atypical ANCA. The immune complex is responsible for complement activation, neutrophil chemotaxis and subsequent phagocytosis, and secretion of neutrophil granular products with vascular damage [13]. The second mechanism is mediated by cytotoxic CD8 + T cells which release interferon- $\gamma$ (INF $\gamma$ ) that recruits and activates macrophages [13]. Finally, in the third case, inflammation and related damage is due to specific antibodies against the cytoplasm of neutrophils [14, 15]. Figure 1 summarizes the main pathogenetic mechanisms of vasculitis.

\section{Clinical Features and Diagnostic Approach}

CNS vasculitis can be primary or secondary [16]. More broadly, CNS vasculitis can be divided into PACNS, where the inflammation is restricted to the vessels of the brain and/or spinal cord, and secondary CNS vasculitis, when the involvement of the brain is associated with other systemic disorders also affecting skin, kidney, lungs, sinuses, cardiovascular system, or joints. A primary vasculitis may occur without any identified underlying cause, whereas other forms of vasculitis can be secondary to a malignancy, drugs of abuse, or medications. In addition, cerebral vasculitis may be secondary to an infectious disease or a non-infectious inflammatory disorder that may be restricted to the CNS or be part of a multiorgan disorder. Since a SOV affecting only the brain is a relatively uncommon condition and because the neurological symptoms are usually non-specific,
Fig. 1 Main pathogenetic mechanisms of vasculitis and blood-brain barrier damage responsible for morphological and pathological organ change, ischemic and hemorrhagic stroke, and encephalopathy. ANCA indicates anti-neutrophil cytoplasmic antibodies; BBB, brain-blood barrier; IFN- $\gamma$, interferon- $\gamma$; ROS, radical oxygen species
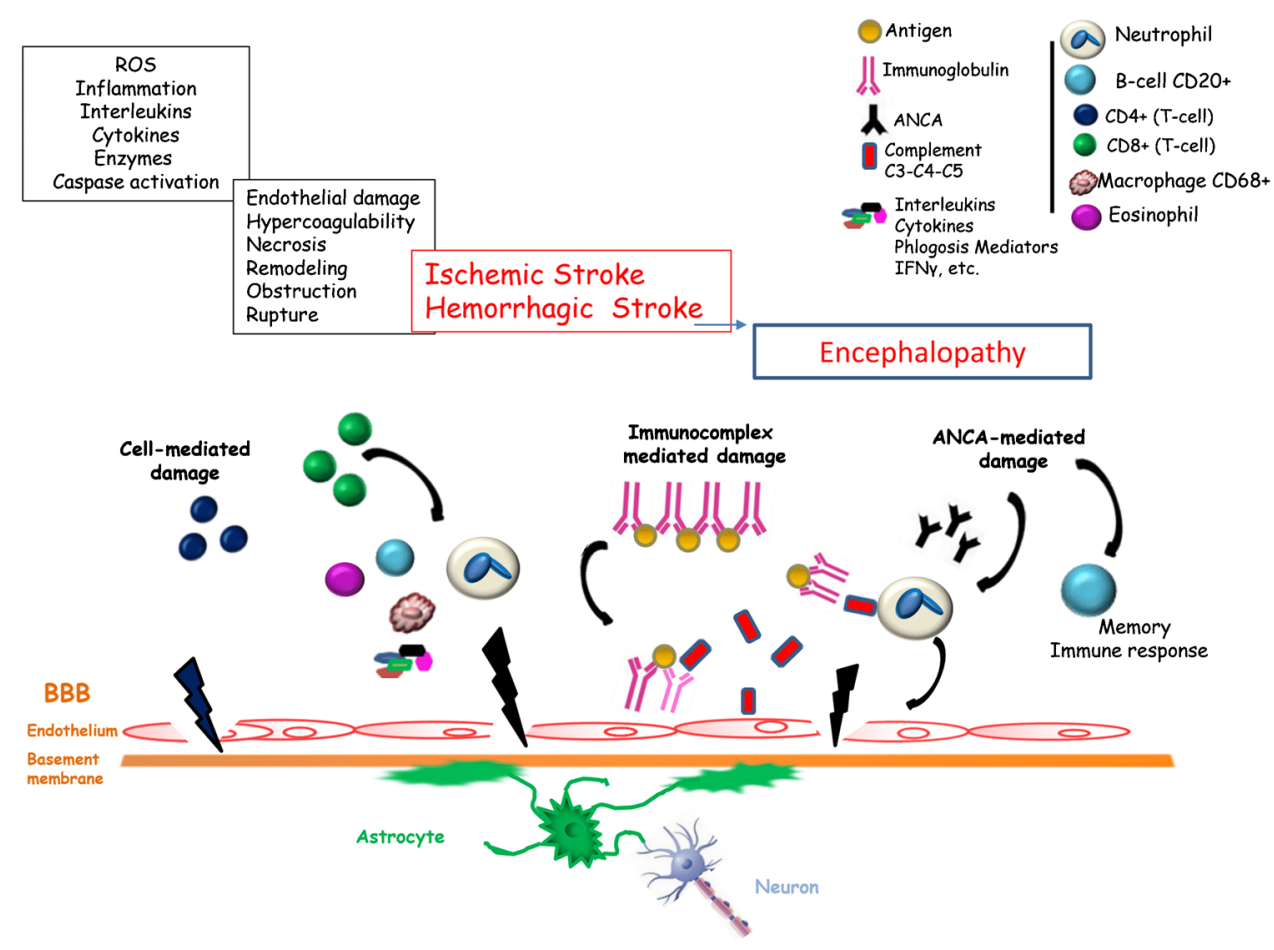
an accurate diagnosis is often challenging. Moreover, the results of laboratory tests and instrumental exams are often not precise enough to diagnose a CNS vasculitis. As a result, a cerebral vasculitis can be both over- and underdiagnosed.

Differential diagnosis of a cerebral vasculitis is also broad. The diagnosis of primary (isolated) vasculitis of the CNS can be very difficult because of the absence of symptoms or signs in other organs or systems. On the other hand, systemic diseases leading to cerebral vasculitis often show a rather stereotyped constellation of clinical symptoms and specific serologic testing abnormalities that make them less difficult to diagnose. Among them, there is also systemic vasculitis from non-autoimmune disorders which include viral infections (e.g., HIV, hepatitis $\mathrm{C}$ virus-associated cryoglobulinemic vasculitis, Coronavirus, Herpes virus, etc.), bacterial and fungal infections, drugs (e.g., hydralazine-associated microscopic polyangiitis, levamisole), and some cancers. Of note, also the new SARS-CoV2 virus (COVID-19) was recently identified as a viral cause of cerebral vasculitis due to an endotheliitis $[17,18]$, and an extensive lymphoplasmacytic perivascular inflammation, as well as a lymphocytic vasculitis [17].

CNS vasculitis secondary to connective tissue autoimmune diseases and systemic vasculitis of small, medium, and large vessels are listed in Table 1 . In this context, it is known that many systemic diseases can be complicated by neurological manifestations through immune-mediated mechanisms or a direct spread to the CNS via the bloodstream through the BBB. The main complications are of neurovascular origin and are caused by endothelial damage, increased coagulability, cascade of chemical mediators, and abnormal inflammatory response. All these mechanisms eventually produce ischemic or hemorrhagic strokes that can affect both intracerebral and subependymal areas, resulting in significant disability. The parenchymal involvement is typically characterized by degeneration, necrosis, demyelination, and reactive gliosis.

In systemic viral infections, the main neurological complications are thrombosis, ischemic and hemorrhagic stroke, meningeal hemorrhage, encephalitis, and acute myelitis, characterized by demyelination, reactive gliosis, and edema [19-23], as well as in bacterial systemic diseases [24], complications of cancer [25], and in some immune-based diseases [26]. Of note, these conditions are included among the differential diagnoses between secondary and primary vasculitis of the nervous system and other systemic dysmetabolic diseases that can lead to stroke or degenerative diseases of the nervous system [2••, 27, 28] (Table 2). When the same mechanisms act systemically toward thromboembolic damage or vasoconstriction at the level of the brain, a determining role of the immune system responsible for secondary vasculitis and stimulation of different types of parenchymal cells can be hypothesized. Therefore, in case of systemic vasculitis, IgG, IgM, IgA, ANCA, C3-C4-C5, and fibrinogen on routinary biopsy specimen are a valuable aid in diagnosis and typing of these conditions. In Table 3 we summarized our complete blood laboratory workup.

Compared to diffuse vasculitis secondarily affecting the brain, PACNS is much less frequent, but they are often fatal, have an unclear etiopathogenesis, and typically involve the CNS without any other systemic involvement [29, 30]. Moreover, unlike systemic and secondary vasculitis, SOV of the brain shows normal blood tests or non-specific findings, such as anemia, leukocytosis, and increased inflammatory markers, and the same holds true for the analysis of cerebrospinal fluid (CSF). CSF findings usually include a mild lymphomonocytic pleocytosis or protein elevation in more than $90 \%$ of patients [2••, 31, 32]. CSF tests in suspected PACNS should search for systemic inflammation including specific antibodies but must also exclude important differential diagnoses. In Table 4 we summarized our complete CSF laboratory workup.

Neuroradiological studies are also important for a correct management and demonstrate cerebral involvement: brain MRI studies (with T1- and T2-weighted imaging, FLAIR, gradient-echo, diffusion weighted imaging, apparent diffusion coefficient, high-resolution T1-weighted imaging after contrast injection with fat suppression and flow compensation to evaluate possible wall enhancement in cerebral arteries, gadolinium-enhanced imaging), spinal cord MRI studies (with T1- and T2-weighted imaging of the entire spinal cord, as well as T1-and T2-weighted axial imaging and gadolinium-enhanced imaging of cord lesions), and vascular imaging studies (conventional digital subtraction angiography [DSA], CTA, and MRA) are the gold standard for the demonstration of vessel stenoses or aneurysms. They should be obtained at presentation, at neurological deteriorations, and during follow-up and should be systematically performed, analyzed, and compared. MRI studies should be also assessed for appropriate clinical correlations, both at presentation and during follow-up. In cerebral vasculitis, both ischemic and hemorrhagic lesions of different ages as well as findings of focal or diffuse inflammation are observed.

However, in SOV cases, frequently only the brain biopsy, although invasive, can provide evidence of diagnosis and exclude other conditions. Nevertheless, a negative biopsy does not fully exclude a PACNS due to the segmental and transmural characteristic of vessel inflammation [27, 30, 33, 34], also considering that PACNS mainly affects small- and medium-sized arteries (serving cortical and juxtacortical areas), spinal cord, and meninges. Among the complications of the vessel itself, aneurysms can develop, as well as stenosis and thrombosis, along with related histological findings [35-41]. As stated, unlike systemic or secondary forms, PACNS vasculitis does not have a clear etiopathogenesis. This is also due to the paucity of pathological data and the limitations of biopsy (Table 5) $[6 \bullet \bullet, 42-51,52 \bullet]$. Although the role of infectious agents 
Table 2 Main mimics of CNS vasculitis

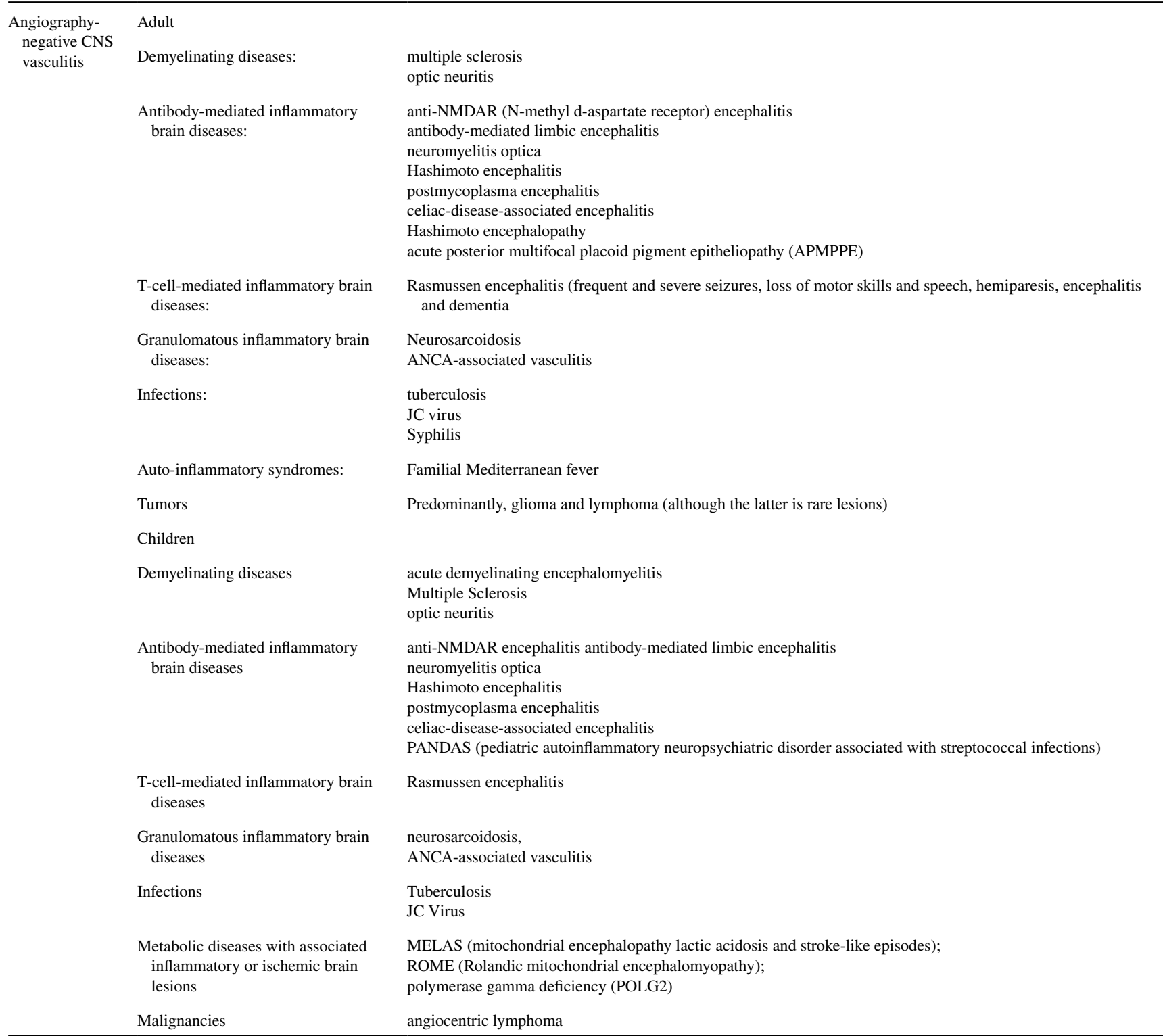


Table 2 (continued)

\begin{tabular}{|c|c|c|}
\hline \multirow{14}{*}{$\begin{array}{l}\text { Angiography- } \\
\text { positive CNS } \\
\text { vasculitis }\end{array}$} & \multirow{2}{*}{\multicolumn{2}{|c|}{$\begin{array}{l}\text { Adult } \\
\text { Arteriosclerosis }\end{array}$}} \\
\hline & & \\
\hline & Vasospastic diseases & $\begin{array}{l}\text { reversible cerebral vasoconstriction syndrome } \\
\text { migraines } \\
\text { vasospasms secondary to hypertension, drug exposure } \\
\text { subarachnoid hemorrhage } \\
\text { eclampsia } \\
\text { pheochromocytoma } \\
\text { Hashimoto encephalopathy } \\
\text { APMPPE }\end{array}$ \\
\hline & \multicolumn{2}{|l|}{$\begin{array}{l}\text { Thromboembolic disease, bacterial } \\
\text { endocarditis }\end{array}$} \\
\hline & \multicolumn{2}{|l|}{ Hemoglobin disorders } \\
\hline & \multicolumn{2}{|l|}{ Antiphospholipid antibody syndrome } \\
\hline & \multicolumn{2}{|l|}{ Fibromuscular dysplasia } \\
\hline & $\begin{array}{l}\text { Genetic diseases associated with } \\
\text { obliterating cerebral vasculopathy: }\end{array}$ & $\begin{array}{l}\text { Degos disease (Köhlmeier-Degos disease or malignant atrophic papulosis [MAP]) } \\
\text { retinocerebral vasculopathy with cerebral leukodystrophy (RVCL) }\end{array}$ \\
\hline & $\begin{array}{l}\text { Other Syndromes with associated } \\
\text { cerebral vasculopathy: }\end{array}$ & $\begin{array}{l}\text { Cogan syndrome [vasculopathy plus inflammatory eye disease (interstitial keratitis) and vestibular auditory } \\
\text { dysfunction] } \\
\text { Susac syndrome (non-inflammatory vasculopathy, retinopathy, hearing loss and encephalopathy) } \\
\text { Sneddon syndrome (progressive non-inflammatory cerebral arteriopathy and livedo) }\end{array}$ \\
\hline & \multicolumn{2}{|l|}{ Children } \\
\hline & Non-inflammatory CNS vasculopathy & $\begin{array}{l}\text { dissection } \\
\text { thromboembolic disease } \\
\text { hemoglobin disorders } \\
\text { aPL (antiphospholipid antibody) syndrome } \\
\text { fibromuscular dysplasia } \\
\text { collagen vascular disorders } \\
\text { focal cerebral angiopathy (Marfan Syndrome, Ehlers-Danlos Syndrome, etc.) } \\
\text { Moyamoya disease (idiopathic) }\end{array}$ \\
\hline & $\begin{array}{l}\text { Conditions associated with cerebral } \\
\text { vasospasms }\end{array}$ & $\begin{array}{l}\text { channelopathies including familiar hemiplegic migraine and calcium channelopathy } \\
\text { reversible vasoconstriction syndrome }\end{array}$ \\
\hline & $\begin{array}{l}\text { Genetic syndromes with associated } \\
\text { vasculopathy }\end{array}$ & $\begin{array}{l}\text { neurofibromatosis type } 1 \\
\text { Down's syndrome } \\
\text { PHACES (posterior fossa malformations-hemangiomas-arterial anomalies-cardiac defects-eye abnormalities- } \\
\text { sternal cleft and supraumbilical raphe syndrome) } \\
\text { homocystinuria }\end{array}$ \\
\hline & $\begin{array}{l}\text { Other syndromes with associated } \\
\text { cerebral vasculopathy }\end{array}$ & $\begin{array}{l}\text { Cogan syndrome } \\
\text { Susac syndrome }\end{array}$ \\
\hline
\end{tabular}

has been hypothesized, given the prevalent granulomatous findings observed histologically, the autoimmune pathway remains the most convincing hypothesis. Literature also indicates a higher rate of ischemic events than intracranial hemorrhages in PACNS, as it occurs in secondary vasculitis [35-41]. Overall, these manifestations can be explained by direct damage to the vessel, along with the inflammatory phenomena, increase in coagulability due to proinflammatory cytokines on endothelial cells, and changes in vasomotor tone. However, unlike systemic vasculitis, the immunological mechanisms that may be involved in PACNS are still not known. Indeed, while direct endothelial damage mediated by antibodies or an indirect damage from the immune system and mediators of inflammation are relevant and known in secondary vasculitis, as well as the response induced by the deposition of immune complexes in the vascular walls with complement and coagulation activation, this evidence is currently lacking in PACNS, although the occurrence of p-ANCA antibodies in CNS vasculitis has been described [53]. What is probably known is that CNS vasculitis is histologically independent entities from systemic vasculitis and, thus, is likely not part of a spectrum within the temporal evolution of the same vasculitis process $[6 \bullet \bullet$. Lastly, a doubtful but intriguing point regards the presence of amyloid in some histological types of vasculitis. This might merely represent the product of vasculitis from chronic alteration of vascular permeability and deposit in damaged walls, but, on the other hand, this can trigger a further inflammatory/autoimmune response and immune-mediated CD20+lymphocyte subpopulation activity [54•]. However, the main granulomatous nature of the histological lesions suggests the possibility of a T-cell-mediated immunological response (T helper-mediated) in response to cytokines produced by dendritic cells, 
Table 3 Main blood laboratory test diagnostic workup of vasculitis

Adult

Routine blood tests

Autoimmune screening

Non-genetic thrombophilic screening

Neoplastic and paraneoplastic screening

Viral and bacterial screening
Complete Blood Count (CBC)

Transaminase (ALT, AST), Gamma GT, Creatinine, Urea

Erythrocyte sedimentation rate (ESR), C-reactive protein (CRP)

Prothrombin time (PT), Partial thromboplastin time (PTT)

Serum Electrophoresis

Cholesterol (total, high-density lipoprotein (HDL), low-density lipoprotein (LDL)), Triglycerides

Ferritin

Lactate dehydrogenase (LDH)

In selected cases (clinically oriented): Genetic Test for HLA-B51

Anti-neutrophil cytoplasmic antibodies (ANCAs)

Anti-double-stranded DNA (Anti-dsDNA) antibodies

Extractable Nuclear Antigen Antibodies (ENA)

Anti-nuclear antibody (ANA)

Anti-Thyroglobulin antibodies (TG)

Anti-thyroid peroxidase antibody (TPO)

In selected cases, if clinically oriented:

- Anti-Mitochondria Antibody (AMA)

- Gastric parietal cell antibodies (APCA)

- Anti-smooth muscle antibodies (ASMA)

- Anti-citrullinated peptide antibody (ACPA)

Rheumatoid factor (RF)

Anti-transglutaminase antibodies

Complement: C3, C4, CH50

Angiotensin-converting enzyme (ACE)

Immunoglobulin (IgA, IgG, IgM)

Cryoglobulins

Lymphocyte Subsets

$\mathrm{IgG} 4$ (if clinically indicated)

Ab anti-NMDAr, AMPA 1 e 2, GABAb1, LGI1 e CASPR2, Ab anti-GluR3 (if indicated)

Anti-beta 2 glycoprotein I autoantibodies (IgG and $\operatorname{IgM}$ )

Anti-Cardiolipin Antibodies (IgG and IgM)

LAC (lupus anticoagulant; in patients NOT on oral anticoagulant drugs)

Vitamin B12

Homocysteine

Folate

C-protein, S-protein, Factor V G1691A and FII G20210A mutation (if clinically indicated)

Prostate-specific antigen (PSA)

CA-125

Antibodies against neuronal antigens (Hu, Yo, Ri, Amphiphysin anti-Ma1, anti-Ma2, anti-CV2 antibodies)

If history of malignancy and clinically indicated: $\beta 2$ microglobulin, Alpha-fetoprotein, CA 19-9, Carcinoembryonic Antigen (CEA)

Anti-HCV antibodies

Anti-HIV antibodies

VDRL (Venereal Diseases Research Laboratories)

Anti-HSV 1/2 Antibodies (IgG and IgM)

Anti-VZV Antibodies (IgG and IgM)

Anti-CMV Antibodies (IgG and IgM)

Anti-EBV Antibodies (IgG and IgM; including anti-EBNA1 Antibodies)

HbsAg

Anti-HBsAg (aHBs), HBcAb and Anti-HbeAb Antibodies

Anti-SARS-CoV-2 Antibodies

PCR against neurotropic virus (in case of probable acute infection)

QuantiFERON

Anti-Treponema antibodies (FTA-ABS/TPHA) 
Table 3 (continued)

\begin{tabular}{ll}
\hline Urinalysis & Basic exams \\
& Urine Electrophoresis \\
& Drug tests (when clinically indicated)
\end{tabular}

Children

Routine blood tests

CBC

Transaminase (ALT, AST), Gamma GT, Creatinine, Urea

ESR, CRP

PT, PTT

Serum Electrophoresis

Cholesterol (total, HDL, LDL), Triglycerides

Ferritin

LDH

In selected cases and if clinically indicated: Genetic Test for HLA-B51

Autoimmune Screening

Anti-neutrophil cytoplasmic antibodies (ANCAs)

Anti-double-stranded DNA (Anti-dsDNA) antibodies

Extractable Nuclear Antigen Antibodies (ENA)

Anti-nuclear antibody (ANA)

Anti-Thyroglobulin antibodies (TG)

Anti-thyroid peroxidase antibody (TPO)

Complement: C3, C4, CH50

Angiotensin-converting enzyme (ACE)

Immunoglobulin (IgA, IgG, IgM)

Lymphocyte Subsets

If clinically indicated:

- Anti-Mitochondria Antibody (AMA)

- Gastric parietal cell antibodies (APCA)

- Anti-smooth muscle antibodies (ASMA)

- Rheumatoid factor

- Anti-transglutaminase antibodies

- Cryoglobulins

- Adenosine deaminase 2 (ADA2) (evaluation of enzymatic activity)

Non-genetic/genetic thrombophilic screening: Anti-beta 2 glycoprotein I autoantibodies (IgG and IgM)

Anti-Cardiolipin Antibodies (IgG and IgM)

LAC (lupus anticoagulant; in patients NOT on oral anticoagulant drugs)

Vitamin B12

Folate

FVW (VIII)

Homocysteine

C Protein, S Protein

ATIII deficiency

Factor V G1691A and FII G20210A mutation

Neoplastic and paraneoplastic screening

In case suspected cases: antibodies against neuronal antigens (Hu, Yo, Ri, Amphiphysin antiMa1, anti-Ma2, anti-CV2 antibodies)

Viral/bacterial screening

Anti-HCV antibodies

Anti-HIV antibodies

Anti-HSV 1/2 Antibodies (IgG and IgM)

Anti-VZV Antibodies (IgG and IgM)

Anti-CMV Antibodies (IgG and IgM)

Anti-EBV Antibodies (IgG and IgM; including anti-EBNA1 Antibodies)

HbsAg

Anti-HBsAg (aHBs), HBcAb and Anti-HbeAb Antibodies

Anti-SARS-CoV-2 Antibodies

PCR against neurotropic virus (in case of probable acute infection)

PPD and/or QuantiFERON TB gold

Mycoplasma antibodies (IgG e IgM)

Anti-Treponema antibodies (FTA-ABS/TPHA)

If clinically indicated:

- VDRL

- Borrelia Burgdorferi antibodies WB 
Table 3 (continued)

\begin{tabular}{ll}
\hline Urinalysis & Basic exams \\
& Urine Electrophoresis (when clinically indicated) \\
& Drug tests (when clinically indicated)
\end{tabular}

AMPA indicates $\alpha$-Ammino-3-idrossi-5-Methyl-4-isossazol-Propionic Acid; anti-CV2, Crossveinless2; CASPR2, Contactin-associated proteinlike 2; CMV, Cytomegalovirus; EBV, Epstein-Barr Virus; Factor II, Prothrombin 20,210 Mutation, also called Mutation FII G20210A; Factor V, Leiden Factor V G1691A; GABAb1, Gamma-aminobutyric acid B receptor; GluR3, Glutamate receptor 3; HBcAb, Hepatitis B Core Antibody; HBeAb, Hepatitis B Envelope Antibody; HBsAg, Hepatitis B Surface Antigen; HCV, Hepatitis C Virus, HIV, Human Immunodeficiency Virus; HSV, Herpes Simplex Virus; HZV Herpes Zoster Virus; LGI1, Leucine-rich glioma inactivated 1; Ma1, anti-Ma2 anti-neuronal proteins; NMDAr, N-methyl-D-aspartate receptor; SARS-Cov 2, Severe acute respiratory syndrome Coronavirus 2; VZV, Varicella Zoster Virus

macrophages, and natural killer (NK) cells. The T-cellmediated response induces the production and release of mediators (such as IFN- $\gamma$, TNF- $\alpha$, TNF- $\beta$, IL-2-6-7-8) that could promote the vasculitis process through a proinflammatory action, a stimulation and production of nitric oxide, and the expression of HLA class I and class II (HLA-I and HLA-II) on endothelial cells, ependymal cells, microglia, and perivascular cells [55].

\section{Clinical Assessment Tools and Diagnostic Criteria}

Current therapy has transformed the prognosis of the PANCS, and this improvement in prognosis highlighted the need for better methods of monitoring disease activity and recording the damage that occurs during the disease. While imaging and laboratory testing including histology are important aspects of diagnosis, they are of limited value in assessing response to therapy or subsequent disease course. Unfortunately, there are not well-validated clinical indices that record disease activity, damage, and the extent of disease in PANCS. Clinical assessment remains the gold standard for evaluating disease progress but requires regular training to ensure standardization. Developing standardized and validated clinical methods to quantify disease activity and damage can allow a detailed assessment of the patient's response to therapy and provide an essential tool for insuring uniformity of patient monitoring for clinical management as well as an essential tool in conducting clinical trials and studies in PANCS (Table 6). The development of biomarkers in future may produce a more accurate description of disease and identify potential targets for therapy as well as predictors of response to drugs. However, the majority of available biomarkers

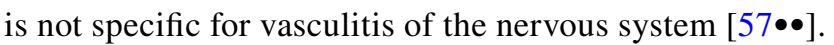

The diagnosis of PANCS is often difficult. There are neither specific clinical features nor a classical clinical course, and no blood or imaging investigations that can confirm the diagnosis. The actual diagnostic criteria are usually based on clinical experience and the evidence from published works. Here we describe a diagnostic approach based on the importance of obtaining tissue, and dividing cases into 'definite' PANCS, when tissue proof is available, and 'possible,' when it is not. Our suggested diagnostic criteria in adults and children are summarized in Table 7.

\section{Adults}

Definite PACNS requires a confirmation through the brain biopsy with specific histopathological patterns [10]. Probable PACNS is so-called when brain biopsy is lacking, and its hypothesis is supported by Digital Subtraction Angiography (DSA) and/or MRI/intracranial MR-Angiography (MRA) and/or intracranial CT-Angiography (CTA) and/or CSF analysis which may reveal lymphocytic pleocytosis and elevated levels of protein [58]. The imaging study of the CNS vessels should demonstrate alternating areas of stenosis, ectasia, or both in more than one vascular bed, unexplained by intracranial arteriosclerosis, reversible cerebral vasoconstriction syndromes (RVCS), or other diseases that may mimic PACNS [7, 25, 28, 37].

\section{Children}

In pediatric subjects (cPACNS), the diagnostic criteria [47, $59,60]$ mandate a newly acquired neurological deficit with histological (definite PACNS) or angiographic (probable PACNS) evidence of CNS vasculitis in the absence of a systemic condition that could explain these findings. Specific subset of angiographically defined cPACNS (largeand medium-sized vessels) are reported:

\section{Principles of Management and Therapy}

1. Vasculitis is often severe diseases with potential permanent disability due to tissue ischemia and infarction and a possible fatal outcome that require prompt recognition and therapy 
Table 4 Cerebrospinal fluid diagnostic workup

\begin{tabular}{|c|c|}
\hline \multicolumn{2}{|l|}{ Adult } \\
\hline Standard test & $\begin{array}{l}\text { Glucose } \\
\text { Chloride } \\
\text { Proteins } \\
\text { Cell count and Cytological evaluation }\end{array}$ \\
\hline Advanced test & $\begin{array}{l}\text { Bacterioscopic test and cultures } \\
\text { Link Index } \\
\text { Anti-HCV antibodies } \\
\text { HbsAg } \\
\text { Anti-HBsAg (aHBs) Antibodies } \\
\text { Anti-HIV antibodies } \\
\text { VDRL (Venereal Diseases Research } \\
\text { Laboratories) } \\
\text { Anti-HSV 1/2 Antibodies (IgG and } \\
\text { IgM) } \\
\text { Anti-VZV Antibodies (IgG and IgM) } \\
\text { Anti-CMV Antibodies (IgG and IgM) } \\
\text { Anti-EBV Antibodies (IgG and IgM) } \\
\text { Anti-HSV 1_2 Antibodies (IgG and } \\
\text { IgM) } \\
\text { Anti-SARS-CoV-2 Antibodies (IgG } \\
\text { and IgM) } \\
\text { Anti-Treponema antibodies } \\
\text { PCR against neurotropic virus (CMV, } \\
\text { HSV, HZV, VZV, EBV, JCV) (in } \\
\text { case of probable acute infection) } \\
\text { Lymphocyte Subsets }\end{array}$ \\
\hline $\begin{array}{l}\text { Suspicion and if clinically } \\
\text { indicated }\end{array}$ & Borrelia Burgdorferi PCR \\
\hline Children & \\
\hline Standard test & $\begin{array}{l}\text { Glucose } \\
\text { Chloride } \\
\text { Proteins } \\
\text { Cell count and Cytological evaluation }\end{array}$ \\
\hline Advanced test & $\begin{array}{l}\text { Bacterioscopic test and cultures } \\
\text { Link Index } \\
\text { HbsAg } \\
\text { Anti-HBsAg (aHBs) Antibodies } \\
\text { Anti-HSV 1/2 Antibodies (IgG and } \\
\text { IgM) } \\
\text { Anti-VZV Antibodies (IgG and IgM) } \\
\text { Anti-CMV Antibodies (IgG and IgM) } \\
\text { Anti-EBV Antibodies (IgG and IgM) } \\
\text { Mycoplasma antibodies (IgG and } \\
\text { IgM) } \\
\text { PCR against neurotropic virus (CMV, } \\
\text { HSV, HZV, VZV, EBV, JCV) (in } \\
\text { case of probable acute infection) }\end{array}$ \\
\hline $\begin{array}{l}\text { In case of suspicion and if } \\
\text { clinically indicated }\end{array}$ & $\begin{array}{l}\text { Anti-Treponema antibodies } \\
\text { Borrelia Burgdorferi PCR }\end{array}$ \\
\hline
\end{tabular}

CMV indicates cytomegalovirus; EBV, Epstein-Barr Virus; HSV, Herpes Simplex Virus; HZV, Herpes Zoster Virus; JCV, John Cunningham Virus; PCR protein chain reaction; SARS-Cov 2, severe acute respiratory syndrome coronavirus 2; VZV, Varicella Zoster Virus

Vasculitis typically has an insidious onset with slow progression, though rarely occurs in acute forms. The multifocal characteristic of the lesions clinically determines non-specific and not always superimposable symptomatology in different patients. Indeed, the clinical presentation is often variable in the absence of pathognomonic signs and symptoms, although headache $(60 \%)$, cognitive disturbances (50\%), focal neurological deficits (mostly stroke or hemorrhage), convulsions, encephalopathy [61-63], and isolated myelopathies have been most described [56].

Overall, however, symptoms and signs can be within a wide spectrum, with focal lesion symptoms less frequent than those caused by multifocal lesions due to segmental or diffuse vessel involvement. For these reasons, the diagnosis of CNS vasculitis or a PACNS is rather complex, also given the lack of validated criteria, and requires a multidisciplinary approach that includes clinical features, laboratory investigations, imaging findings, and biopsy in selected cases.

2. Some forms of vasculitis are associated with severe neurological complications that significantly affects patient's prognosis

Regardless of the primary or secondary form, vasculitis is a determining factor for neurological complications. The subtle inflammatory process that typically affects vessels within different regions of the CNS or PNS is responsible for severe and often unpredictable complications, sometimes with poor prognosis. Brain complications from both systemic and primary vasculitis are basically represented by acute vascular events. Thrombosis, ischemic stroke, and hemorrhagic lesions, with tissue degeneration and inflammatory involvement of other structures (such as leptomeninges), are responsible for several morphological and functional deficits, causing death in severely affected cases. These neurovascular conditions, though common, remain non-specific, thus opening a wide spectrum of differential diagnoses.

3. Clinical course of vasculitis can range from fulminant to very mild forms and may fluctuate in clinical signs

As a rule, clinical presentation of both primary and secondary vasculitis of the brain is very heterogeneous, including focal or multifocal deficits. Neurological symptoms depend on the affected vascular district, the extent of the process, and the duration of the disease. Therefore, symptoms can be non-specific, subtle, or overt, and the course may be subacute or chronic, up to some striking manifestations, often including neurological deficits from vascular and non-vascular complications [61].

Patients with PACNS typically present with a gradual and mild headache, often associated with signs and symptoms of cognitive impairment. Only later they can develop focal neurological deficits. The clinical course may be rapidly progressive over few days or weeks, or can be insidious over many months, with prolonged periods of stability. Conversely, patients with granulomatous angiitis present with headache, cognitive changes, and increased CSF protein content, with or without pleocytosis $[62,63]$. Hemiparesis, quadriparesis, 
Table 5 Main histopathological findings from biopsy and postmortem brain tissue samples. PubMed research ranged from January 2016 to May 2021

\begin{tabular}{|c|c|}
\hline Study & Histological findings on biopsy and postmortem tissue \\
\hline Wang et al. [42] & $\begin{array}{l}\text { Brain tissue edema } \\
\text { Degeneration } \\
\text { Necrosis } \\
\text { Glial cell hyperplasia } \\
\text { Tissue cell response Scattered lymphocytic infiltration } \\
\text { Vascular wall thickening Intra-vascular and perivascular lymphocytes } \\
\text { Few granulocytes }\end{array}$ \\
\hline Sundaram et al. [43] & Lymphocytic, necrotizing, and granulomatous patterns \\
\hline Suthiphosuwan et al. [56] & $\begin{array}{l}\text { Vasculocentric trans-mural lymphocytic infiltration CD20 +(B-cell lymphocytes), CD } 3+\text { (T-cell lymphocytes) } \\
\text { Macrophages }(\mathrm{CD} 163+)\end{array}$ \\
\hline Caputi et al. [44] & Angiocentric trans-mural lymphocytic infiltration CD3+ \\
\hline Salvarani et al. [45] & $\begin{array}{l}\text { Granulomatous inflammatory pattern with deposits of } \beta \text {-amyloid peptide } \\
\text { A granulomatous and necrotizing pattern } \\
\text { Acute necrotizing pattern } \\
\text { Lymphocytic pattern }\end{array}$ \\
\hline Chang et al. $[6 \bullet \bullet]$ & $\begin{array}{l}\text { Demyelination } \\
\text { Lymphocytic vasculitis } \\
\text { Necrotic vasculitis with inflammation and fibrinoid necrosis } \\
\text { Granulomatous vasculitis (granuloma with lymphocytes and macrophages) }\end{array}$ \\
\hline Takatsu et al. [46] & Vasculitis with fibrinoid necrosis \\
\hline Denny et al. [47] & $\begin{array}{l}\text { Chronic inflammatory infiltrate with CD3-positive T cells including both CD } 4+\text { and CD } 8+\text { and CD20 }+(B \\
\text { cells), and macrophages }(\mathrm{CD} 68+)\end{array}$ \\
\hline Wilson et al. [48] & Perivascular and intramural chronic inflammation with stenosis of the lumen \\
\hline Spence et al. [49] & Mural thickening with diffuse lymphocytic infiltration with fibrinoid necrosis \\
\hline Benson et al. [50] & Transmural lymphocytic infiltration \\
\hline Han et al. [51] & Inflammatory infiltration and granulomas \\
\hline Van Rooij et al. [52•] & Thickening of the tunica intima with inflammatory cells in the tunica media \\
\hline
\end{tabular}

Table 6 Clinical assessment tools in patients with PANCS for a possible use in clinical practice

\begin{tabular}{ll}
\hline Clinical scales for adults & Clinical scales for young subjects $(<18$ years of age) \\
\hline - NIHSS (NIH stroke/scale score, neurological deficit) & - PED NIHSS (Pediatric NIH stroke/scale score, neurological deficit) \\
- MoCA scale (cognitive decline) & - Age-related intelligence and developmental scales (Wechsler, Griffiths) \\
- Modified Rankin Scale (mRS, degree of disability or dependence) & - ABAS (adaptive behavior) \\
- HRQoL SF-36 (Health related quality of life) & - PSOM-SNE (Pediatric stroke outcome measure short neuro exam) \\
- Hospital Anxiety and Depression Scale (HADS) & - PedsQL (Pediatric quality of life) \\
& - CBCL (Child behavior check list)
\end{tabular}

and lethargy can frequently develop and need prompt diagnosis due to the poor prognosis of their natural history.

4. There is a likelihood of excess morbidity and mortality due to missing diagnosis and therefore undertreatment

When a striking event of stroke or hemorrhage does not occur, the symptomatic spectrum is particularly difficult to assess and the diagnosis of vasculitis with cerebral involvement is very challenging. This is in part due to the insidious onset of symptoms and broad differential diagnosis. Diagnosis is especially challenging in SOV which do not present with the same serologic findings or constellation of clinical symptoms as seen with systemic vasculitis. Failure or delay in the diagnosis and treatment is responsible for an excess of morbidity and mortality. In these cases, the neurological damage can be by permanent.

5. Histopathological confirmation of vasculitis is essential for accurate diagnosis, as well as a correct methodology for achieving it

Brain biopsy remains the gold standard in diagnosing PACNS $[44,56]$. Of note, the biopsy is not only useful for confirming a vasculitis, but also for excluding other dis-

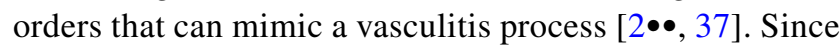


Table 7 Diagnostic criteria of PANCS in adults and children

Adults

Histopathological patterns of vasculitis

Granulomatous

Lymphocytic

Necrotizing

Children

Angiographically defined cPACNS

Non-progressive cPACNS

Progressive cPACNS

Angiography-negative cPACNS

(small-sized vessels)
Microscopic findings (brain biopsy)

Vasculocentric mononuclear inflammation with multinucleated giant cells arranged in epithelioid granulomas with transmural destruction of the vessel wall. Leptomeningeal and intraparenchymal vessels may be involved

Perivascular lymphomonocyte infiltrate with involvement of the vessel wall. Rare and occasional plasma cells may be present

Transparietal fibrinoid necrosis of vessels with associated inflammatory infiltrate

Findings and disease course

A devastating, monophasic inflammatory vessel disease of the CNS with stable MRI at 3 months

A chronic inflammatory disease defined by new segments of stenosis on angiography after 3 months of disease when untreated

$\mathrm{n} / \mathrm{a}$ small vessels, arterioles, and capillaries are involved in primary CNS vasculitis, transmural and segmental signs of inflammation are the main diagnostic histological findings. A morphological diagnosis of vasculitis, indeed, requires the occurrence of transmural vasculocentric inflammation with vascular wall damage, with or without fibrinoid necrosis [56]. The morphological evaluation of the damaged vessel wall, with the assessment of lymphocyte populations, multinucleated giant cells, and transmural fibrinoid necrosis are all key elements for the diagnosis of a cerebral vasculitis. The next step is the typing of the PACNS and the exclusion of differential diagnoses, which basically include secondary vasculitis (such as those due to degenerative, infectious, and tumor lesions) [62]. Some authors have also confirmed the results of the biopsy in vivo with the results obtained from autopsies [45, 52•, 64]. In both cases, PACNS histologically presents as granulomatous, necrotizing, or lymphocytic, although mixed morphologic types often occur. The histological findings of vasculitis are often associated with evidence of ischemic stroke due to stenosis or total obstruction of the damaged vessel and alterations in coagulation, as well as of intraparenchymal/submeningeal hemorrhage when the damaged vessel ruptures, or of a post-thrombotic consequence as it happens in ischemic or hemorrhagic stroke due to other diseases. Histological patterns of this vasculitis are reported below [45]. Granulomatous vasculitis is the most common pattern with infiltration of the vascular wall from $\mathrm{T}$ lymphocytes and macrophages, which subsequently organize into granulomas with giant cells (Fig. 2A). Damage to the wall with fragmentation of the elastic fibers and reworking with proliferation of the intima causes subsequent fibrosis and vessel occlusion. Differential diagnoses include all granulomatous diseases that produce sarcoid-like granulomas, including sarcoidosis [65]. In these cases, the exclusive localization of the brain and the absence of systemic manifestations or laboratory data may be helpful. The deposition of amyloid can also be associated with the granulomatous histotype [43, 45, 66]. Lymphocytic vasculitis is characterized by predominantly lymphocytic inflammation, with a small amount of plasma cells affecting the entire thickness of the vascular wall (Fig. 2B,C,D). Indeed, some authors describe a clear vasculocentric transmural lymphocytic infiltration involving the vessels with CD3-positive (CD4 + and CD8 +) and CD20-positive lymphocytes, along with other minor elements such as macrophages (as in our case series). The main differential diagnosis of this histotype is leukodystrophy $[42-45,47,48,50,52 \bullet, 56,59,60]$. Necrotizing vasculitis is less common and is characterized by transmural fibrinoid necrosis that mainly affects small muscular arteries with rupture of the internal elastic lamina and rupture of the vessel or aneurysmal dilations. In addition, an inflammatory lymphomonocyte infiltrate may be present (Fig. 1E,F) [43, 45, 46, 49, 67]. Histological findings are similar to those observed in polyarteritis nodosa with transmural fibrinoid necrosis and may indicate the occurrence of similar underlying pathological mechanisms $[5,30]$. Fibrinoid necrosis of the vessel wall may also predispose to vessel rupture, thus resulting in intracranial hemorrhage. A vasculocentric inflammatory infiltrate is considered diagnostic to primary vasculitis when other morphological aspects and clinical signs indicative of other pathologies are absent. Indeed, these infiltrates can be observed also in association with other infectious and neoplastic diseases, as well as in primary and secondary vasculopathies. For instance, the differential diagnosis with lymphomas needs to evaluate the atypia of lymphoid cells and the expression of specific markers. Similarly, the necrotizing finding can also be present in some infectious diseases with both parenchymal and vascular involvement, such as atypical mycobacteriosis [68, 69]. Finally, 

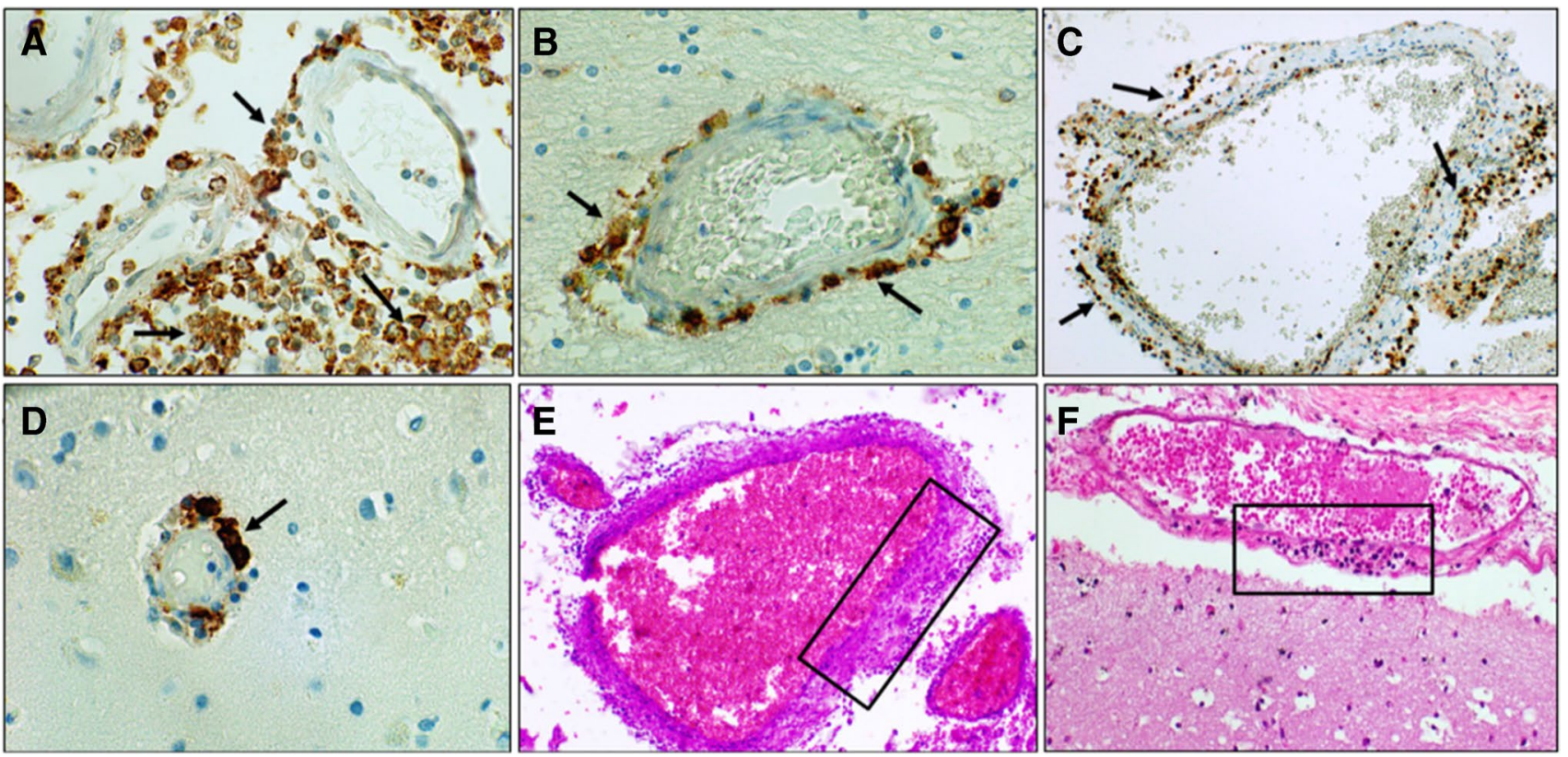

Fig. 2 Main anatomopathological findings from authors' autoptic studies. A: Granulomatous pattern: arrows indicate CD-68+macrophages arranged around the vessel and with initial aggregation in a sarcoid-like granuloma ( $\times 40$ magnification). B-D: Lymphocytic pattern: arrows indicate $\mathrm{T}$ lymphocytes $(\mathrm{CD} 3+)$ around vessels with

although the brain biopsy has a consolidated role in the oncological pathology of the CNS, it is worth to mention that despite the standardization brain biopsy, this approach is still poorly practiced and affected by some limitations, especially in non-neoplastic diseases [70]. First, the brain biopsy is a highly specialistic invasive procedure that can be complicated by intracerebral hemorrhage, seizures, transient altered mental status, cerebral infarction, and CSF leak also when performed by trained operators and in specialized centers. Second, the diagnostic accuracy of brain biopsy remains far from being pathognomonic, and the histological diagnosis is generally limited from the characteristics of segmentary and multifocality of most of vasculitis processes. Biopsy may also show negative or non-specific findings, which may be due to prolonged time to biopsy, non-lesioned biopsy, prior steroid treatment, or inadequate specimen sampling. Also, a guided biopsy does not always provide an adequate and comprehensive sample of the vascular lesion, and, on the other hand, a negative biopsy does not fully rule out a diagnosis of vasculitis. Finally, the pathologist's training and expertise in the processing of samples and search for specific markers is of crucial importance, as well as the collaboration with neurosurgeons in the choice, timing, and modality of sampling. The diagnosis of some vasculitis requires specific methods, such as immunofluorescence for the identification of $\operatorname{IgG}, \operatorname{IgM}, \operatorname{IgG}$, complement, and fibrinogen. The risk of negative neurological outcomes, the poor negative different caliber (B and D: CD3 $+\times 40$ magnification; $\mathrm{C}: \mathrm{CD} 8+\times 20$ magnification). E-F: Necrotizing pattern: the black box indicates a particular of degeneration and necrosis of the vessel wall with the presence of lymphocytes $(H \& E$ stain $\times 40)$. Images from G. Mansueto's case studies

predictive value of the biopsy, and reliance on the clinician's judgment make the diagnosis of vasculitis with a brain biopsy challenging. A correct indication posed by clinicians, together with an accurate medical history and clinical examination, simplifies and directs the pathologist's evaluation toward the method of choice and, hopefully, a definitive diagnosis. The motto is that "no biopsy of any organ is foreign or independent of the rest of the body." Fig. 2 shows the main vasculitis and immunohistochemical histological patterns. Immunohistochemistry with anti-CD3, anti-CD8, and anti-CD68 was performed on paraffinized brain samples using the detection method described in the literature $[71,72]$.

6. Empiric trials with immunosuppressive and immunomodulating therapy should never be considered as a substitute for a confirmed diagnosis of vasculitis

Physicians treating vasculitis must choose the sequence and combination of available immunosuppressant and immunomodulating therapies to induce and sustain remission and treat relapses, recognizing the possible beneficial and adverse effects. The standard of care for the treatment of vasculitis, notably ANCA-associated vasculitis (AAV), has been evolving in response to many factors [73]. First, the steady influx of data from multicenter, national, and international collaborative, evidence-based randomized clinical trials (RCT) 
and observational cohorts in adult vasculitis. Second, while many vasculitis still lacks well-validated measures of disease activity or state for use in clinical trials, there have nonetheless been advances in standardized approaches to conducting clinical trials as advocated by the EULAR and its collaborators worldwide [74]. Third, the influence of gene-wide association studies (GWAS) and biobank data such as the UK Biobank to elucidate risk gene loci, single nucleotide polymorphism (SNP) and human HLA polymorphisms in disease clusters and population cohorts [75]. Such inherited and environmental factors, gene-gene interactions, epigenetic factors, and other influences upon the immunopathogenesis of vasculitis have had important theoretical importance for the performance of RCTs in vasculitis subtypes, as well as relevance for screening studies and timing of therapy.

7. Treatments are initially guided toward stabilization of the blood-brain barrier (BBB), followed by maintenance immunosuppressive therapy directed both at the humoral and cellmediated autoimmune and inflammatory mechanisms

The goal of treatment should be the rapid control of the inflammatory response and the stabilization of the BBB while protecting the brain from further injuries. Methylprednisolone has been the first-line agent administered intravenously at a dose of $30 \mathrm{mg} / \mathrm{kg} / \mathrm{d}$ to a maximum of $1 \mathrm{~g} / \mathrm{d}$ for 3 to 5 days, followed by 1 to $2 \mathrm{mg} / \mathrm{kg} / \mathrm{d}$ of oral corticosteroids (CS) to a maximum of $60 \mathrm{mg} / \mathrm{d}$ of prednisone [76]. After stabilization, the choice of
Fig. 4 (A) The suggested treatment algorithm for children-PACNS, angiography-negative cPACNS (small-sized vessels), and (B) for children-PACNS, angiography-positive cPACNS (large- and mediumsized vessels) $[78,79]$

immunosuppressive treatment is directed toward the primary inflammatory or vasculitis process. Induction therapy with CS and pulse cyclophosphamide cyclosporine (CYC), followed by maintenance therapy with azathioprine (AZA) or mycophenolate mofetil (MMF), has been recommended in cPACNS. In Fig. 3 is summarized our proposed treatment algorithm for adult PACNS. Children with SV-cPACNS were treated in an open-label study with CYC in doses of 500 to $750 \mathrm{mg} / \mathrm{m}^{2}$ as monthly infusions for 6 months, followed with maintenance therapy with AZA of $1 \mathrm{mg} / \mathrm{kg} / \mathrm{d}$ and a target dose of 2 to $3 \mathrm{mg} / \mathrm{kg} / \mathrm{d}$, and MMF at titrated doses of 800 to $1200 \mathrm{mg} / \mathrm{m}^{2} / \mathrm{d}$ followed for up to 24 months using pediatric stroke outcome measures (PSOM). Among 19 such patients, 13 completed 24 months of follow-up, of whom 9 had a good neurological outcome by PSOM scoring, 8 experienced disease flares, and 4 achieved remissions of disease. MMF was more effective than AZA. Rituximab may be appropriate therapy at doses of $375 \mathrm{mg} / \mathrm{m}^{2}$ for 4 consecutive weeks or $500 \mathrm{mg} / \mathrm{m}^{2}$ weekly for 2 weeks in cPACNS, as was recently reported in SV-cPACNS [77]. Figure 4, panel A and B summarizes the suggested treatment algorithms for children-PACNS, in angiography-positive (large- and medium-sized vessels) and angiography negative (smallsized vessel), as well as for adult PACNS [78, 79].
Fig. 3 The suggested treatment algorithms for adult-PACNS

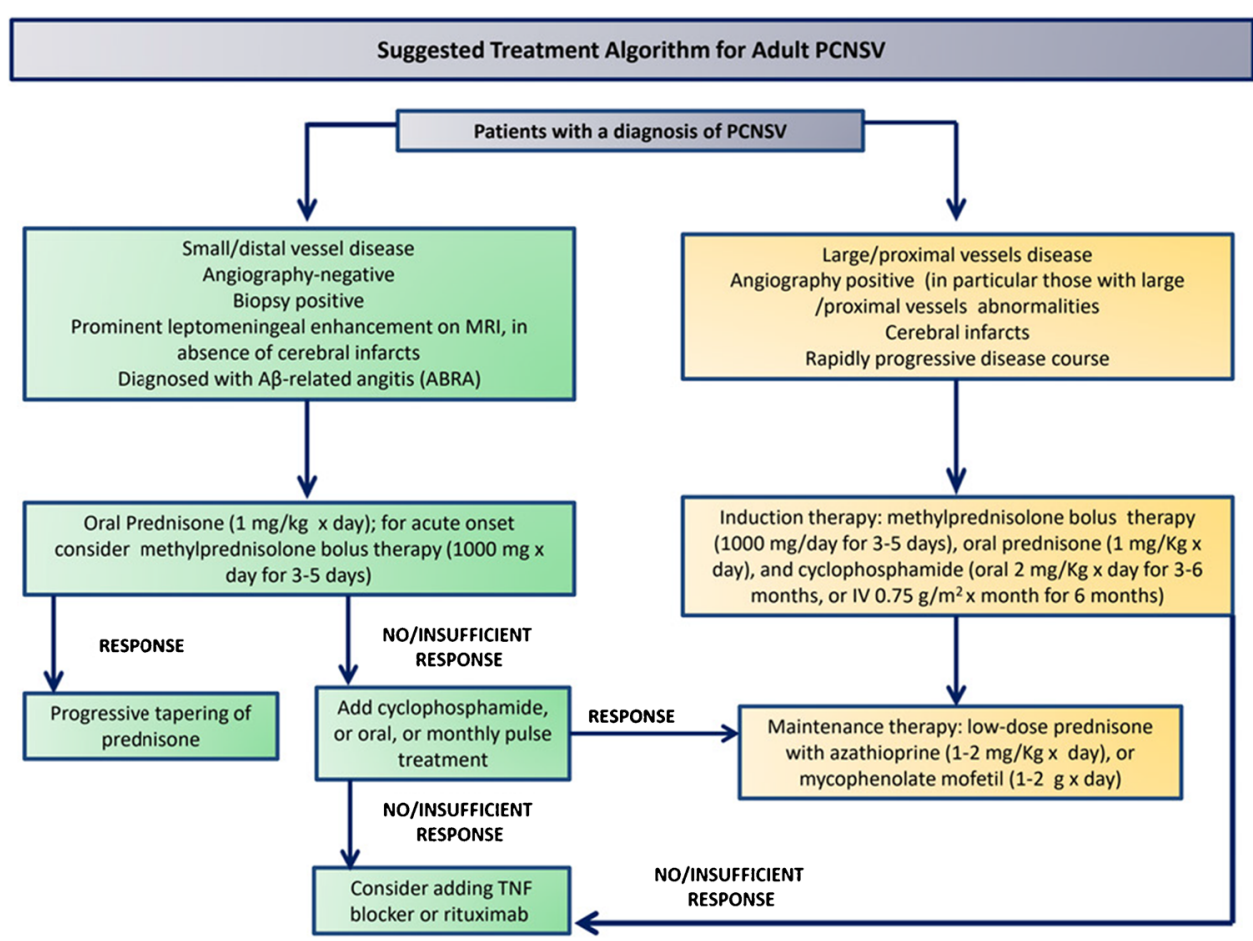




\section{Suggested Treatment Algorithm for Children-PACNS}

\section{Angiography- negative cPACNS (Small size vessels)}

All patients should be treated with antithrombotic therapy symptomatically as needed, including antieplleptic and antipsychotic drugs. Vitamin D and calcium should be supplemented during steroid administration. [ Low-molecular-weight heparin $100 \mathrm{UI} / \mathrm{kg}$ BID for 2 weeks and then Acetylsalicylic Acid $(5 \mathrm{mg} / \mathrm{kg}$ for day - max $100 \mathrm{mg}$ ) for 24 months]. Concomitant cotrimoxazole prophylaxis is administered if needed

Small/distal vessel disease
Angiography-negative
Biopsy positive
Prominent leptomeningeal enhancement on MRI, in
absence of cerebral infarcts

Induction therapy: for acute onset IV Methylprednisolone pulse ( $30 \mathrm{mg} / \mathrm{kg}$ - $\mathrm{max} 1 \mathrm{~g}$ per day for 5-7 days); Oral Prednisone ( $2 \mathrm{mg} / \mathrm{kg}$ day - $\max 60 \mathrm{mg}$ ) than $1.5 \mathrm{mg} / \mathrm{kg} / \mathrm{d}$ for $1 \mathrm{month}$, and $1 \mathrm{mg} / \mathrm{kg} / \mathrm{d}$ for $1 \mathrm{month}$, then weekly tapering in 12 months

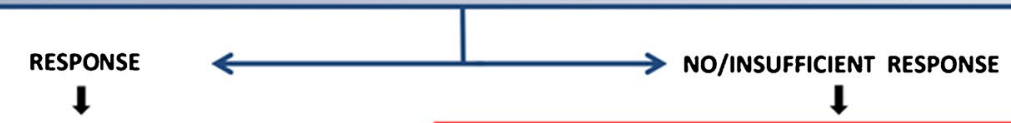

6 months steroid therapy: Oral Prednisone $(2$ $\mathrm{mg} / \mathrm{kg}$ day - $\max 60 \mathrm{mg}$ ) for 3 months, 1.5 $\mathrm{mg} / \mathrm{kg} / \mathrm{d}$ for $1 \mathrm{month}$, and $1 \mathrm{mg} / \mathrm{kg} / \mathrm{d}$ for 1 month, then weekly tapering

Oral Prednisone ( $2 \mathrm{mg} / \mathrm{kg}$ day - max $60 \mathrm{mg}$ ) for $1 \mathrm{month}$; tapering the dose by $0.25 \mathrm{mg} / \mathrm{kg}$ every 2 weeks to reach a daily dose of 1 $\mathrm{mg} / \mathrm{kg}$ per day at the end of the third month, then tapering the dose since $0.2 \mathrm{mg} / \mathrm{kg}$ by the end of month 6 maintaining it until the end of month 12; Starting at month 13 , reducing the dose to $0.1 \mathrm{mg} / \mathrm{kg}$ per day for further 6 months and keep it to month 24 .

Add: Cyclophosphamide ( $500-750 \mathrm{mg} / \mathrm{m}^{2}$ monthly for 6 months) + - IVIG ( $2 \mathrm{mg} / \mathrm{kg}$ in 2-5 days for 6 months)

Consider adding Rituximab $(375 \mathrm{mg} / \mathrm{m2}$ ) every week for 1 month and then monthly for 6 months. Prednisone $(2 \mathrm{mg} / \mathrm{kg}$ day - max $60 \mathrm{mg}$ )

A monthly tapering over 12 months (see above)
Maintenance therapy: oral mycophenolate mofetil ( 800 $1200 \mathrm{mg} / \mathrm{m}^{2}$ divided BID) or oral azathioprine $(2-3 \mathrm{mg} / \mathrm{kg}$, max $150 \mathrm{mg}$ daily) and oral Prednisone ( $2 \mathrm{mg} / \mathrm{kg}$ day max $60 \mathrm{mg}$ ) monthly tapering over 12 months (see above)

\section{Suggested Treatment Algorithm for Children-PACNS Angiography - positive cPACNS (Large and medium size vessels)}

\section{Non-Progressive cPACNS}

Monophasic inflammatory vessel disease of the CNS

NO new areas of inflammation in previously unaffected vessels on repeat neuroimaging after three months of diagnosis

IV Methylprednisolone pulse

( $30 \mathrm{mg} / \mathrm{kg} \cdot \max 1 \mathrm{~g}$ per day for $3-5$ days)

Oral Prednisone: $2 \mathrm{mg} / \mathrm{kg} /$ die (maximum $60 \mathrm{mg}$ ) for $1 \mathrm{month}$, $1.5 \mathrm{mg} / \mathrm{kg} / \mathrm{d}$ for $1 \mathrm{month}$, and $1 \mathrm{mg} / \mathrm{kg} / \mathrm{d}$ for 1 month, then rapid weekly tapering if no imaging

(adjunctive corticosteroids MAY prevent recurrentischemic events and improve neurological outcome)

\section{Progressive cPACNS}

Angiography positive (in particular those with large/proximal vessel abnormalities)

Presence of cerebral infarcts and/or new segments of stenosis on angiography after 3 months of disease when untreated Rapidly progressive disease course

Induction therapy: IV Methylprednisolone pulse $(30 \mathrm{mg} / \mathrm{kg}$ - $\max$ $1 \mathrm{~g}$ per day for $3-5$ days)

Oral Prednisone: $2 \mathrm{mg} / \mathrm{kg} /$ die (maximum $60 \mathrm{mg}$ ) for 1 month, 1.5 $\mathrm{mg} / \mathrm{kg} / \mathrm{d}$ for $1 \mathrm{month}$, and $1 \mathrm{mg} / \mathrm{kg} / \mathrm{d}$ for 1 month, then weekly tapering in 12 months

Cyclophosphamide $(500-750 \mathrm{mg} / \mathrm{m} 2$ monthly for 6 months

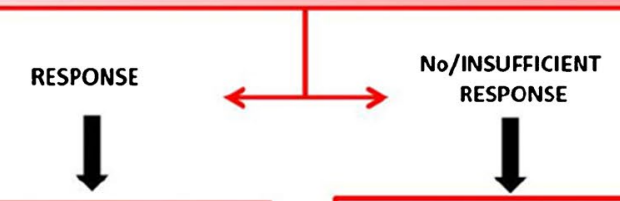

Maintenance therapy: oral mycophenolate mofetil ( $800-1200 \mathrm{mg} / \mathrm{m} 2$ divided BID) or oral azathioprine $(2-3 \mathrm{mg} / \mathrm{kg}$, max $150 \mathrm{mg}$ daily) and oral Prednisone $(2 \mathrm{mg} / \mathrm{kg}$ day - max $60 \mathrm{mg}$ ) monthly tapering over 12 months
Consider adding Rituximab ( $375 \mathrm{mg} / \mathrm{m} 2$ ) every week for 1 month and then monthly for 6 months.

Oral Prednisone $(2 \mathrm{mg} / \mathrm{kg}$ day - max $60 \mathrm{mg}$ ) monthly tapering over 12 months 


\section{Concluding Remarks and Future Perspectives}

Primary CNS vasculitis is a challenging condition due to the broad clinical manifestations and variable specificity and sensitivity of both laboratory and imaging diagnostic tools, with brain biopsy to be performed whenever possible. Large vessel primary CNS vasculitis should be managed with steroids and CYC, whereas small vessel forms with steroids alone. The most important differential diagnosis is the RCVS that may occur without thunderclap headache, whereas other differential diagnoses include secondary CNS vasculitis and non-inflammatory vasculopathies. Overall, our understanding of PACNS and the characterization of its range and subsets has been advanced, although we still need to clarify methods of diagnosis and management. Biomarker and outcome investigations might identify risk factors for an aggressive course, thus leading to treatment tailored to disease severity. Effectiveness and safety profiles of intravenous pulse and oral immunosuppressive treatments, and clarification of which patients need them at disease onset, need to be established yet. Other drug types should be considered as substitutes for immunosuppressors in selected subgroups. Moreover, since primary PACNS is uncommon, an international collaborative registry and repositories of biological specimens would help with the development of standardized classification and diagnostic criteria, help to define homogeneous patient groups for randomized clinical trials, and might aid clinicians in differentiation of primary CNS vasculitis from its much more common mimickers.

\section{Declarations}

Conflict of Interest Gelsomina Mansueto, Giuseppe Lanza, Francesco Fisicaro, Danielle Alaouieh, Emily Hong, Sara Girolami, Marco Montella, Alessandro Feola, and Mario Di Napoli each declare no potential conflicts of interest.

Human and Animal Rights and Informed Consent This article does not contain any studies with human or animal subjects performed by any of the authors.

\section{References}

Papers of particular interest, published recently, have been highlighted as:

- Of importance

$\bullet$ Of major importance

1. Jennette JC, Falk RJ, Bacon PA, Basu N, Cid MC, Ferrario F, Flores-Suarez LF, Gross WL, Guillevin L, Hagen EC, et al. 2012 Revised International Chapel Hill Consensus Conference Nomenclature of Vasculitides. Arthritis Rheum. 2013;65:1-11. https://doi.org/10.1002/art.37715.
2.• Dutra LA, de Souza AW, Grinberg-Dias G, Barsottini OG, Appenzeller S. Central nervous system vasculitis in adults: An update. Autoimmun Rev. 2017;16:123-31. https://doi.org/10. 1016/j.autrev.2016.12.001. A well written review on the diagnosis and management of PCNSV, secondary vasculitis of CNS and RCVS.

3. Beachy N, Satkowiak K, Gwathmey KG. Vasculitic Neuropathies. Semin Neurol. 2019;39:608-19. https://doi.org/10.1055/s0039-1688990.

4. Gwathmey KG, Tracy JA, Dyck PJB. Peripheral Nerve Vasculitis: Classification and Disease Associations. Neurol Clin. 2019;37:303-33. https://doi.org/10.1016/j.ncl.2019.01.013.

5. Miller DV, Salvarani C, Hunder GG, Brown RD, Parisi JE, Christianson TJ, Giannini C. Biopsy findings in primary angiitis of the central nervous system. Am J Surg Pathol. 2009;33:35-43. https://doi.org/10.1097/PAS.0b013e318181e097.

6.• Chang HB, Gao M, Zhang JN, Cao WD, Guo SL, Wang P, Cheng G, Zhao HL. Retrospective Analysis of 28 Cases Confirmed for Primary Angiitis of the Central Nervous System by Biopsy. J Stroke Cerebrovasc Dis. 2020;29: 105400. https://doi.org/10. 1016/j.jstrokecerebrovasdis.2020.105400. It suggests some good sense guidelines in diagnosis and treatment PACNS patients. An early role of biopsy is suggested together with an aggressive treatment regimen.

7. Daneman R, Prat A. The blood-brain barrier. Cold Spring Harb Perspect Biol. 2015;7: a020412. https://doi.org/10.1101/cshpe rspect.a020412.

8. Obermeier B, Daneman R, Ransohoff RM. Development, maintenance and disruption of the blood-brain barrier. Nat Med. 2013;19:1584-96. https://doi.org/10.1038/nm.3407.

9. Younger DS. The Blood-Brain Barrier: Implications for Vasculitis. Neurol Clin. 2019;37:235-48. https://doi.org/10.1016/j.ncl. 2019.01.009.

10. Carmona FD, Lopez-Mejias R, Marquez A, Martin J, GonzalezGay MA. Genetic Basis of Vasculitides with Neurologic Involvement. Neurol Clin. 2019;37:219-34. https://doi.org/10.1016/j. ncl.2019.01.006.

11. Rahmattulla C, Mooyaart AL, van Hooven D, Schoones JW, Bruijn JA, Dekkers OM, Bajema IM. Genetic variants in ANCA-associated vasculitis: a meta-analysis. Ann Rheum Dis. 2016;75:1687-92. https://doi.org/10.1136/annrh eumdis-2015-207601.

12. Shavit E, Alavi A, Sibbald RG. Vasculitis-What Do We Have to Know? A Review of Literature. Int J Low Extrem Wounds. 2018;17:218-26. https://doi.org/10.1177/1534734618804982.

13. Ozen S, Batu ED. Vasculitis Pathogenesis: Can We Talk About Precision Medicine? Front Immunol. 1892;2018:9. https://doi. org/10.3389/fimmu.2018.01892.

14. Yates M, Watts R. ANCA-associated vasculitis. Clin Med (Lond). 2017;17:60-4. https://doi.org/10.7861/clinmedicine. 17-1-60.

15. Kallenberg CG, Heeringa P. Pathogenesis of vasculitis. Lupus. 1998;7:280-4. https://doi.org/10.1191/096120398678920109.

16. Younger DS. Eleven Themes in the History of Systemic and Nervous System Vasculitides. Neurol Clin. 2019;37:149-70. https://doi.org/10.1016/j.ncl.2019.01.001.

17. Timmons GM, Rempe T, Bevins EA, Goodwill V, Miner A, Kavanaugh A, Ritter M, Graves JS. CNS Lymphocytic Vasculitis in a Young Woman With COVID-19 Infection. Neurol Neuroimmunol Neuroinflamm. 2021;8(5):e1048. https://doi.org/10.1212/ NXI.0000000000001048.

18. Kirschenbaum D, Imbach LL, Rushing EJ, Frauenknecht KBM, Gascho D, Ineichen BV, Keller E, Kohler S, Lichtblau M, Reimann RR, et al. Intracerebral endotheliitis and microbleeds are neuropathological features of COVID-19. Neuropathol Appl Neurobiol. 2021;47:454-9. https://doi.org/10.1111/nan.12677. 
19. Elkind MSV, Boehme AK, Smith CJ, Meisel A, Buckwalter MS. Infection as a Stroke Risk Factor and Determinant of Outcome After Stroke. Stroke. 2020;51:3156-68. https://doi.org/10.1161/ STROKEAHA.120.030429.

20. Yachou Y, El Idrissi A, Belapasov V, Ait Benali S. Neuroinvasion, neurotropic, and neuroinflammatory events of SARSCoV-2: understanding the neurological manifestations in COVID-19 patients. Neurol Sci. 2020;41:2657-69. https://doi. org/10.1007/s10072-020-04575-3.

21. Fisicaro F, Di Napoli M, Liberto A, Fanella M, Di Stasio F, Pennisi M, Bella R, Lanza G, Mansueto G. Neurological Sequelae in Patients with COVID-19: A Histopathological Perspective. Int J Environ Res Public Health. 2021;18(4):1415. https://doi.org/10. 3390/ijerph18041415.

22. Bradshaw MJ, Venkatesan A. Herpes Simplex Virus-1 Encephalitis in Adults: Pathophysiology, Diagnosis, and Management. Neurotherapeutics. 2016;13:493-508. https://doi.org/10.1007/ s13311-016-0433-7.

23. Mansueto G. COVID-19: Brief check through the pathologist's eye (autopsy archive). Pathol Res Pract. 2020;216: 153195. https://doi.org/10.1016/j.prp.2020.153195.

24. Pagliano P, Spera AM, Ascione T, Esposito S. Infections causing stroke or stroke-like syndromes. Infection. 2020;48:323-32. https://doi.org/10.1007/s15010-020-01415-6.

25. Dardiotis E, Aloizou AM, Markoula S, Siokas V, Tsarouhas K, Tzanakakis G, Libra M, Kyritsis AP, Brotis AG, Aschner M, et al. Cancer-associated stroke: Pathophysiology, detection and management (Review). Int J Oncol. 2019;54:779-96. https://doi. org/10.3892/ijo.2019.4669.

26. Kidd DP. Neurological complications of Behcet's syndrome. J Neurol. 2017;264:2178-83. https://doi.org/10.1007/ s00415-017-8436-9.

27. Salvarani C, Brown RD Jr, Christianson TJH, Huston J 3rd, Morris JM, Giannini C, Hunder GG. Primary central nervous system vasculitis mimicking brain tumor: Comprehensive analysis of 13 cases from a single institutional cohort of 191 cases. J Autoimmun. 2019;97:22-8. https://doi.org/10.1016/j.jaut.2018.10.001.

28. de Boysson H, Boulouis G, Dequatre N, Godard S, Neel A, Arquizan C, Detante O, Bloch-Queyrat C, Zuber M, Touze E, et al. Tumor-Like Presentation of Primary Angiitis of the Central Nervous System. Stroke. 2016;47:2401-4. https://doi.org/ 10.1161/STROKEAHA.116.013917.

29. Jacob S. Primary angiitis of the central nervous system (PACNS) - a rare and serious, but treatable entity. Neurol India. 2019;67:942-4. https://doi.org/10.4103/0028-3886.263180.

30. Giannini C, Salvarani C, Hunder G, Brown RD. Primary central nervous system vasculitis: pathology and mechanisms. Acta Neuropathol. 2012;123:759-72. https://doi.org/10.1007/ s00401-012-0973-9.

31. Salvarani C, Brown RD Jr, Hunder GG. Adult primary central nervous system vasculitis. Lancet. 2012;380:767-77. https://doi. org/10.1016/S0140-6736(12)60069-5.

32. Mandal J, Chung SA. Primary Angiitis of the Central Nervous System. Rheum Dis Clin North Am. 2017;43:503-18. https:// doi.org/10.1016/j.rdc.2017.06.001

33. Torres J, Loomis C, Cucchiara B, Smith M, Messe S. Diagnostic Yield and Safety of Brain Biopsy for Suspected Primary Central Nervous System Angiitis. Stroke. 2016;47:2127-9. https://doi. org/10.1161/STROKEAHA.116.013874.

34. Raghavan A, Wright JM, Huang Wright C, Shammassian BH, Onyewadume L, Momotaz H, Burant CJ, Sajatovic M, Carandang R, Furlan A, et al. Concordance of angiography and cerebral biopsy results for suspected primary central nervous system vasculitis: A multi-center retrospective review. Clin Neurol Neurosurg. 2019;185:105482. https://doi.org/10.1016/j.clineuro. 2019.105482
35. Peng LJ, Qian HR, Mao LL, Xia DY, Qi XK. A clinical analysis of 5 patients with infratentorial primary angiitis of central nervous system. Zhonghua Nei Ke Za Zhi. 2017;56:284-9. https:// doi.org/10.3760/cma.j.issn.0578-1426.2017.04.009.

36. Soun JE, Song JW, Romero JM, Schaefer PW. Central Nervous System Vasculopathies. Radiol Clin North Am. 2019;57:111731. https://doi.org/10.1016/j.rcl.2019.07.005.

37. Cho TA, Jones A. CNS vasculopathies: Challenging mimickers of primary angiitis of the central nervous system. Best Pract Res Clin Rheumatol. 2020;34: 101569. https://doi.org/10.1016/j. berh.2020.101569.

38. Kalashnikova LA, Dobrynina LA, Legenko MS. Primary central nervous system vasculitis. Zh Nevrol Psikhiatr Im S S Korsakova. 2019;119:113-23. https://doi.org/10.17116/jnevro2019 119081113.

39. Lucke M, Hajj-Ali RA. Advances in primary angiitis of the central nervous system. Curr Cardiol Rep. 2014;16:533. https://doi org/10.1007/s11886-014-0533-0.

40. Stanley E, Murphy S, Kavanagh E. Letter by Stanley et al Regarding Article, "Primary Angiitis of the Central Nervous System Magnetic Resonance Imaging Spectrum of Parenchymal, Meningeal, and Vascular Lesions at Baseline". Stroke. 2017;48: e178. https://doi.org/10.1161/STROKEAHA.117.017518.

41. Boulouis G, de Boysson H, Naggara O. Response by Boulouis et al to Letter Regarding Article, "Primary Angiitis of the Central Nervous System: Magnetic Resonance Imaging Spectrum of Parenchymal, Meningeal, and Vascular Lesions at Baseline". Stroke. 2017;48: e179. https://doi.org/10.1161/STROKEAHA. 117.017609.

42. Wang LJ, Kong DZ, Guo ZN, Zhang FL, Zhou HW, Yang Y. Study on the Clinical, Imaging, and Pathological Characteristics of 18 Cases with Primary Central Nervous System Vasculitis. J Stroke Cerebrovasc Dis. 2019;28:920-8. https://doi.org/10. 1016/j.jstrokecerebrovasdis.2018.12.007.

43. Sundaram S, Menon D, Khatri P, Sreedharan SE, Jayadevan ER, Sarma P, Pagnoux C, Sylaja PN. Primary angiitis of the central nervous system: Clinical profiles and outcomes of 45 patients. Neurol India. 2019;67:105-12. https://doi.org/10.4103/00283886.253578 .

44. Caputi L, Erbetta A, Marucci G, Pareyson D, Eoli M, Servida M, Parati E, Salsano E. Biopsy-proven primary angiitis of the central nervous system mimicking leukodystrophy: A case report and review of the literature. J Clin Neurosci. 2019;64:42-4. https://doi.org/10.1016/j.jocn.2019.03.021.

45. Salvarani C, Brown RD Jr, Christianson T, Miller DV, Giannini C, Huston J 3rd, Hunder GG. An update of the Mayo Clinic cohort of patients with adult primary central nervous system vasculitis: description of 163 patients. Medicine (Baltimore). 2015;94: e738. https://doi.org/10.1097/MD.0000000000000738.

46. Takatsu H, Komatsu T, Fukasawa N, Fukuda T, Iguchi Y. Spontaneously changing MRI findings of primary central nervous system vasculitis: A case report. J Clin Neurosci. 2021;83:125-7. https://doi.org/10.1016/j.jocn.2020.11.012.

47. Denny AM, Das SK. A case of central nervous system vasculitis presenting as a mass-like lesion. Childs Nerv Syst. 2019;35:1223-6. https://doi.org/10.1007/s00381-018-04034-7.

48. Wilson N, Pohl D, Michaud J, Doja A, Miller E. MRI and clinicopathological correlation of childhood primary central nervous system angiitis. Clin Radiol. 2016;71:1160-7. https://doi.org/10. 1016/j.crad.2016.07.013.

49. Spence S, Ng D, Casault C. Atypical presentation of fulminant primary central nervous system angiitis. J Neuroimmunol. 2019;330:1-4. https://doi.org/10.1016/j.jneuroim.2019.01.019.

50. Benson CE, Knezevic A, Lynch SC. Primary Central Nervous System Vasculitis With Optic Nerve Involvement. J 
Neuroophthalmol. 2016;36:174-7. https://doi.org/10.1097/ WNO.0000000000000328.

51. Han X, Pang Z, Wang Z, Xu S, Lin Y. A case of primary angiitis of the central nervous system presenting with diffuse cerebral microbleeds and recurrent intracranial hemorrhage. Neurol Sci. 2019;40:417-9. https://doi.org/10.1007/s10072-018-3595-8.

52.• Van Rooij JL, Rutgers DR, Spliet WG, Frijns CJ. Vessel wall enhancement on MRI in the diagnosis of primary central nervous system vasculitis. Int J Stroke. 2018;13:NP24-7. https:// doi.org/10.1177/1747493018789276. The use of MRI imaging in differential diagnosis.

53. Harland TA, Seinfeld J, Cava LF, Neumann RT, Roark C, Kumpe D, Case D. Anti-neutrophil cytoplasmic antibody associated central nervous system vasculitis with brain and spinal cord subarachnoid hemorrhage: A rare case report and review of the literature. J Clin Neurosci. 2019;62:253-5. https://doi. org/10.1016/j.jocn.2018.12.001.

54. Strunk D, Schulte-Mecklenbeck A, Golombeck KS, Meyer Zu Horste G, Melzer N, Beuker C, Schmidt A, Wiendl H, Meuth $\mathrm{SG}$, Gross CC, et al. Immune cell profiling in the cerebrospinal fluid of patients with primary angiitis of the central nervous system reflects the heterogeneity of the disease. J Neuroimmunol. 2018;321:109-16. https://doi.org/10.1016/j.jneuroim. 2018.06.004. The biological basis for understanding cerebrospinal fluid resulta in pazients with PACNS.

55. Kraemer M, Becker J, Horn PA, Schwitalla JC, Keyvani K, Metz I, Wegner C, Bruck W, Schlamann M, Heinemann FM, et al. Association of primary central nervous system vasculitis with the presence of specific human leucocyte antigen gene variant. Clin Neurol Neurosurg. 2017;160:137-41. https://doi. org/10.1016/j.clineuro.2017.06.009.

56. Suthiphosuwan S, Bharatha A, Hsu CC, Lin AW, Maloney JA, Munoz DG, Palmer CA, Osborn AG. Tumefactive Primary Central Nervous System Vasculitis: Imaging Findings of a Rare and Underrecognized Neuroinflammatory Disease. AJNR Am J Neuroradiol. 2020;41:2075-81. https://doi.org/ 10.3174/ajnr.A6736.

57.• Strunk D, Schmidt-Pogoda A, Beuker C, Milles LS, Korsukewitz C, Meuth SG, Minnerup J. Biomarkers in Vasculitides of the Nervous System. Front Neurol. 2019;10:591. https:// doi.org/10.3389/fneur.2019.00591. Inflammatory markers, antibodies, cerebrospinal fluid analysis, imaging, and biopsy, are all insufficient to meet all current challenges in diagnosis of PACNS. We suggest the use of biomarkers as an approach to extend current knowledge and, ultimately, improve patient management.

58. Ruland T, Wolbert J, Gottschalk MG, Konig S, SchulteMecklenbeck A, Minnerup J, Meuth SG, Gross CC, Wiendl H, Meyer Zu Horste G. Cerebrospinal Fluid Concentrations of Neuronal Proteins Are Reduced in Primary Angiitis of the Central Nervous System. Front Neurol. 2018;9:407. https:// doi.org/10.3389/fneur.2018.00407.

59. Deng J, Fang F, Wang XH, Ge M, He LJ, Zhang N. Small vessel-childhood primary angiitis of the central nervous system: a case report and literature review. Zhonghua Er Ke Za Zhi. 2018;56:142-7. https://doi.org/10.3760/cma.j.issn.0578-1310. 2018.02.014.

60. Elbers J, Halliday W, Hawkins C, Hutchinson C, Benseler SM. Brain biopsy in children with primary small-vessel central nervous system vasculitis. Ann Neurol. 2010;68:602-10. https://doi.org/10.1002/ana.22075.

61. Smitka M, Bruck N, Engellandt K, Hahn G, Knoefler R, von der Hagen M. Clinical Perspective on Primary Angiitis of the
Central Nervous System in Childhood (cPACNS). Front Pediatr. 2020;8:281. https://doi.org/10.3389/fped.2020.00281.

62. Byram K, Hajj-Ali RA, Calabrese L. CNS Vasculitis: an Approach to Differential Diagnosis and Management. Curr Rheumatol Rep. 2018;20:37. https://doi.org/10.1007/ s11926-018-0747-z.

63. Younger DS. Granulomatous Angiitis: Twenty Years Later. Neurol Clin. 2019;37:267-77. https://doi.org/10.1016/j.ncl. 2019.01.011.

64. Powers WJ. Primary angiitis of the central nervous system: diagnostic criteria. Neurol Clin. 2015;33:515-26. https://doi.org/10. 1016/j.ncl.2014.12.004.

65. Saygin D, Jones S, Sundaram P, Calabrese LH, Messner W, Tavee JO, Hajj-Ali RA. Differentiation between neurosarcoidosis and primary central nervous system vasculitis based on demographic, cerebrospinal and imaging features. Clin Exp Rheumatol. 2020;38(Suppl 124):135-8.

66. de Boysson H, Zuber M, Naggara O, Neau JP, Gray F, Bousser MG, Crassard I, Touze E, Couraud PO, Kerschen P, et al. Primary angiitis of the central nervous system: description of the first fifty-two adults enrolled in the French cohort of patients with primary vasculitis of the central nervous system. Arthritis Rheumatol. 2014;66:1315-26. https://doi.org/10.1002/art. 38340.

67. Mizuno Y, Shigeto H, Yamada T, Maeda N, Suzuki SO, Kira J. A case of primary central nervous system vasculitis diagnosed by second brain biopsy and treated successfully. Rinsho Shinkeigaku. 2016;56:186-90. https://doi.org/10.5692/clinicalneurol. cn-000847.

68. Mansueto G, Di Vito A, Belluomo C, Murino P, Natella V, Camastra C, Presta I, Malara N, de Rosa G, Donato G, et al. A case of intravascular large B cell lymphoma: New clinical and immunohistochemical findings. Neuropathology. 2016;36:496503. https://doi.org/10.1111/neup.12300.

69. Russo CV, Sacca F, Paternoster M, Buonomo AR, Gentile I, Scotto R, Brescia Morra V, Mansueto G. Post-mortem diagnosis of invasive pulmonary aspergillosis after alemtuzumab treatment for multiple sclerosis. Mult Scler. 2020;26:123-6. https://doi. org/10.1177/1352458518813110.

70. Noronha C, Figueiredo G, Pinheiro C, Carvalho E, Calheiros A, Pires MM, Taipa R. Brain biopsy in suspected non-neoplastic neurological disease. Acta Neurochir (Wien). 2019;161:113947. https://doi.org/10.1007/s00701-019-03910-8.

71. Mansueto G, Costa D, Capasso E, Varavallo F, Brunitto G, Caserta R, Esposito S, Niola M, Sardu C, Marfella R, et al. The dating of thrombus organization in cases of pulmonary embolism: an autopsy study. BMC Cardiovasc Disord. 2019;19:250. https://doi.org/10.1186/s12872-019-1219-8.

72. Verze P, Somma A, Imbimbo C, Mansueto G, Mirone V, Insabato L. Melanotic schwannoma: a case of renal origin. Clin Genitourin Cancer. 2014;12:e37-41. https://doi.org/10.1016/j. suronc.2009.06.003.

73 Hoffman GS. L52. Vasculitis treatment: is it time to change the standard of care for ANCA-associated vasculitis? Presse Med. 2013;42:643-50. https://doi.org/10.1016/j.lpm.2013.01.047.

74. Navon Elkan P, Pierce SB, Segel R, Walsh T, Barash J, Padeh S, Zlotogorski A, Berkun Y, Press JJ, Mukamel M, et al. Mutant adenosine deaminase 2 in a polyarteritis nodosa vasculopathy. $\mathrm{N}$ Engl J Med. 2014;370:921-31. https://doi.org/10.1056/NEJMo a1307362.

75. Schrader ML, Hochman JS, Bulkley BH. The heart in polyarteritis nodosa: a clinicopathologic study. Am Heart J. 1985;109:1353-9. https://doi.org/10.1016/0002-8703(85) 90365-5. 
76. Beuker C, Schmidt A, Strunk D, Sporns PB, Wiendl H, Meuth SG, Minnerup J. Primary angiitis of the central nervous system: diagnosis and treatment. Ther Adv Neurol Disord. 2018;11:1756286418785071. https://doi.org/10.1177/17562 86418785071 .

77. Keenan P, Brunner J, Quan AS, Smitka M, Hahn G, Pain CE, Hafner R, Speth F, Gerstl L, Hedrich CM. Diagnosis and Treatment of Small Vessel Childhood Primary Angiitis of the Central Nervous System (sv-cPACNS): An International Survey. Front Pediatr. 2021;9: 756612. https://doi.org/10.3389/fped.2021. 756612.
78. Kim G, Chitnis T. Child Neurology: Primary angiitis of the CNS. Neurology. 2017;89:e268-71. https://doi.org/10.1212/WNL. 0000000000004718.

79. Cellucci T, Benseler SM. Central nervous system vasculitis in children. Curr Opin Rheumatol. 2010;22:590-7. https://doi.org/ 10.1097/BOR.0b013e32833c723d.

Publisher's Note Springer Nature remains neutral with regard to jurisdictional claims in published maps and institutional affiliations.

\section{Authors and Affiliations}

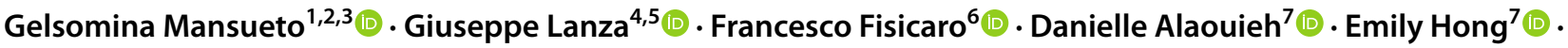

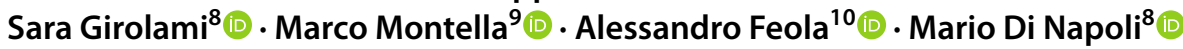

Gelsomina Mansueto

gelsomina.mansueto@unicampania.it; mansueto.g@inwind.it

Giuseppe Lanza

glanza@oasi.en.it

Francesco Fisicaro

drfrancescofisicaro@gmail.com

Danielle Alaouieh

DAAlaouieh@salud.unm.edu

Emily Hong

EmHong@salud.unm.edu

Sara Girolami

girolamisara97@gmail.com

Marco Montella

marco.montella@unicampania.it

Alessandro Feola

alex.feola@gmail.com

1 Department of Advanced Medical and Surgical Sciences (DAMSS), University of Campania "Luigi Vanvitelli", Piazza L. Miraglia 2, 80138 Naples, Italy

2 Clinical Department of Laboratory Services and Public Health-Legal Medicine Unit, University of Campania "Luigi Vanvitelli", via Luciano Armanni 5, 80138 Naples, Italy
3 Pathology-Unit of Federico II University, via S. Pansini 3, 80131 Naples, Italy

4 Department of Surgery and Medical-Surgical Specialties, University of Catania, Via Santa Sofia 78, 95123 Catania, Italy

5 Clinical Neurophysiology Research Unit, Oasi Research Institute-IRCCS, Via Conte Ruggero 73, 94018 Troina, Italy

6 Department of Biomedical and Biotechnological Sciences, University of Catania, Via Santa Sofia 97, 95123 Catania, Italy

7 School of Medicine, University of New Mexico, Albuquerque, NM, USA

8 Neurological Service, SS Annunziata Hospital, Viale Mazzini 100, 67039 Sulmona, L'Aquila, Italy

9 Mental and Physical Health and Preventive Medicine Department, University of Campania "Luigi Vanvitelli", via Luciano Armanni 5, 80138 Naples, Italy

10 Department Experimental Medicine, University of Campania, 80138 Naples, Italy 